\title{
Lifestyle Interventions with a Focus on Nutritional Strategies to Increase Cardiorespiratory Fitness in Chronic Obstructive Pulmonary Disease, Heart Failure, Obesity, Sarcopenia, and Frailty
}

\author{
Hayley E. Billingsley ${ }^{1,2}$, Paula Rodriguez-Miguelez ${ }^{2}{ }^{(}$, Marco Giuseppe Del Buono ${ }^{3}(0)$, \\ Antonio Abbate ${ }^{1}$, Carl J. Lavie ${ }^{4}$ and Salvatore Carbone 1,2,*(D) \\ 1 Department of Internal Medicine, VCU Pauley Heart Center, Virginia Commonwealth University, \\ Richmond, VA 23284, USA; hayley.billingsley@vcuhealth.org (H.E.B.); antonio.abbate@vcuhealth.org (A.A.) \\ 2 Department of Kinesiology \& Health Sciences, College of Humanities \& Sciences, Virginia Commonwealth \\ University, Richmond, VA 23284, USA; prodriguezmig@vcu.edu \\ 3 Department of Cardiovascular and Thoracic Sciences, Catholic University of the Sacred Heart, \\ 00168 Rome, Italy; marcodelbuono@hotmail.it \\ 4 Department of Cardiovascular Diseases, Ochsner Clinical School, New Orleans, LA 70121, USA; \\ clavie@ochsner.org \\ * Correspondence: scarbone@vcu.edu; Tel.: +1-804-628-3980
}

Received: 26 September 2019; Accepted: 15 November 2019; Published: 21 November 2019

\begin{abstract}
Cardiorespiratory fitness $(\mathrm{CRF})$ is an independent predictor for all-cause and disease-specific morbidity and mortality. CRF is a modifiable risk factor, and exercise training and increased physical activity, as well as targeted medical therapies, can improve CRF. Although nutrition is a modifiable risk factor for chronic noncommunicable diseases, little is known about the effect of dietary patterns and specific nutrients on modifying CRF. This review focuses specifically on trials that implemented dietary supplementation, modified dietary pattern, or enacted caloric restriction, with and without exercise training interventions, and subsequently measured the effect on peak oxygen consumption $\left(\mathrm{VO}_{2}\right)$ or surrogate measures of CRF and functional capacity. Populations selected for this review are those recognized to have a reduced $\mathrm{CRF}$, such as chronic obstructive pulmonary disease, heart failure, obesity, sarcopenia, and frailty. We then summarize the state of existing knowledge and explore future directions of study in disease states recently recognized to have an abnormal CRF.
\end{abstract}

Keywords: cardiorespiratory fitness; peak oxygen consumption; cardiopulmonary exercise testing; chronic obstructive pulmonary disease; heart failure; obesity; sarcopenia; frailty

\section{Introduction}

Cardiorespiratory fitness (CRF), often expressed as maximal oxygen consumption $\left(\mathrm{VO}_{2}\right.$ max) in healthy individuals or peak $\mathrm{VO}_{2}$ in those with limitations to exercise, reflects the maximal amount of oxygen that can be taken up, perfused and transported in the blood, absorbed, and utilized during strenuous exercise [1]. The gold standard of $\mathrm{VO}_{2}$ measurement is cardiopulmonary exercise testing (CPET), as it allows for the evaluation of the cardiovascular (CV), respiratory, and muscular responses to maximal exercise encompassed under the term CRF [2]. Recently, CRF has been proposed as a vital sign due to its strong inverse association with all-cause and CV disease (CVD) mortality, which is stronger than many traditional risk factors such as type 2 diabetes mellitus (T2DM) and smoking [1,3], and independent of sex and race [4]. While CRF is best established as a predictor of all-cause- and CVD-specific mortality, it has also been associated with decreased mortality from 
cancer [5,6]. Importantly, improvements or maintenance in CRF over time are associated with lowered all-cause mortality risk [7]; even in older adults, those with the highest CRF have the lowest risk of all-cause mortality [3]. In adulthood, however, there is an average physiologic decline in $\mathrm{VO}_{2}$ max of about $10 \%$ per decade, regardless of physical activity (PA) level [8]. Notably, PA also decreases with age, especially vigorous activity capable of modulating CRF [9]. Therefore, achieving and maintaining the highest level of CRF possible in early adulthood is important for lowering mortality risk in all individuals, even in those classified as low risk for CVD $[4,10]$.

Importantly, although CRF is determined by many factors that cannot be modified, such as age, sex, and underlying disease state(s), in many instances, CRF remains a modifiable risk factor [11]. Exercise training (ET), defined as repeated, structured activity to maintain or increase physical fitness, and increased PA, which encompasses all bodily movement performed by skeletal muscles (SM) resulting in movement, are indeed the most established methods of increasing CRF in apparently healthy individuals [12], as well as those with noncommunicable diseases [13-16]. The use of some medications (e.g., renin-angiotensin-aldosterone system inhibitors, hydralazine, digoxin, ivabradine) in populations with impaired CRF, such as heart failure (HF), has also led to increases in peak $\mathrm{VO}_{2}[2,17]$. Less is known about nutritional strategies to improve CRF; however, dietary interventions have the ability to modify and improve other CV and metabolic risk factors for mortality, such as body weight [18], body composition [19], blood pressure (BP) [20], lipids [21], and inflammation [22], as well as hard endpoints, such as incidence of T2DM [23], CVD [24], and breast cancer [25]. In this review, we explore the effects of nutritional strategies to improve CRF in patients with chronic diseases, with a focus on chronic obstructive pulmonary disease (COPD), HF, obesity, sarcopenia, and frailty. Sarcopenia, obesity, and their combined presence referred to as sarcopenic obesity are body composition abnormalities associated with an impairment in CRF [26]. While obesity refers to an increased amount of fat mass (FM) that affects health, sarcopenia is a progressive loss of SM mass (SMM), as well as strength and functionality of this tissue [27]. These noncommunicable disease states were selected, as CPET and surrogate field tests estimating CRF have not routinely been included as part of clinical and research assessment in all chronic disease populations, especially in regards to nutrition interventions. Finally, emerging populations that may benefit from nutrition intervention on CRF and future directions are discussed.

\section{Chronic Obstructive Pulmonary Disease}

COPD is a life-threatening lung disorder associated with airflow obstruction, exercise intolerance, and overall impairment of health. Disabling symptoms, including dyspnea and fatigue, and lower exercise capacity have been associated with a higher risk of mortality in individuals with COPD [28]. The mechanisms behind exercise intolerance in this population are, however, not fully understood due to the multifactorial mechanisms that contribute to it. Pulmonary limitations caused by poor elastic recoil, increased airways resistance, increased pulmonary vascular resistance, endothelial dysfunction, impaired cardiac output, peripheral muscle dysfunction, and poor nutritional status seem to contribute to this pathological process in a different fashion. Thus, patients often complain of exertional dyspnea, fatigue, muscle weakness, and leg fatigue. Pulmonary rehabilitation (PR) represents a comprehensive intervention that combines ET and disease management and is commonly used to improve patients' physical and psychological condition [29]. Benefits of PR specifically associated with exercise intolerance include increased CRF, improved muscle strength and endurance, as well as reduced symptoms of dyspnea [29]. The implementation of PR in the post-hospitalization period not only reduces the risk of rehospitalization but also mortality [30].

\subsection{Assessment of CRF in COPD}

Considering that the assessment of exercise capacity through CPET is not widely available and may be intimidating to some patients, other field tests have been developed for an easier and more accessible measure of functionality in certain populations. One specific example is the 6-min walk 
test (6MWT), which is predictive of mortality in COPD patients. This test is considered a good assessment of functional capacity, although there is an acknowledged learning effect that needs to be considered when interpreting the results [31,32]. Notably, the $6 \mathrm{MWT}$, as other walking tests, does not provide insights on the determinants responsible for the functional limitation (i.e., CV vs. pulmonary vs. SM), which can, in fact, be determined with CPET. Similarly, the incremental shuttle walking test (ISWT) measures distance walked and correlates well with peak $\mathrm{VO}_{2}$ in COPD, predicting survival and hospital re-admission in this population [33]. Lastly, the endurance shuttle walking test (ESWT) also evaluates endurance capacity and has been proposed as another tool to evaluate CRF in COPD [33]. However, some limitations have been described with this test, and its use has not been validated yet. Nutrition interventions aimed at improving exercise tolerance are often combined with PR with the intention of increasing the effects of ET on CRF [34]. A variety of nutritional adjuncts to PR have been studied, including creatine [35-37], omega-3 (N-3) polyunsaturated fatty acids (PUFA) [38], dietary nitrates [39-41], micronutrient supplementation [42-44], and nutrition support supplementation [45-50]. Notably, the specifics of ET in combined nutrition and PR interventions are often vaguely specified outside of modality of ET, frequency, and total time of visits.

\subsection{Creatine Supplementation in COPD}

Dietary supplementation with creatine monohydrate has been used to enhance the response to high-intensity ET in healthy populations [51]. Creatine monohydrate increases the amount of phosphorylated creatine (PCr) available for ATP synthesis during strenuous exercise and contributes to $\mathrm{PCr}$ resynthesis [35]. Importantly, PCr content has been demonstrated to be lower in subjects with COPD than healthy age-matched subjects [52]. In a randomized, double-blind placebo-controlled trial combining PR and creatine supplementation in patients with COPD (mild-to-moderate severity), creatine has not shown any modulation on CRF defined as changes in peak $\mathrm{VO}_{2}$ or distance walked on ISWT $[35,36]$. Creatine supplementation combined with PR has also failed to improve aerobic endurance over placebo measured by the ESWT [37]. There have been mixed reports regarding the effect of creatine supplementation combined with PR on muscle strength and endurance in patients with COPD [35,36]. Fat-free mass (FFM), a surrogate measure of SMM and a major determinant of CRF [27,53], was increased with creatinine supplementation and PR $[35,36]$. This may, however, be due to intramuscular fluid retention, which would be read as an increase in FFM, and not necessarily SMM [35,36]. Similar results have been previously described in healthy elderly individuals undergoing dietary creatine supplementation and resistance ET, with associated improvements in FFM and isometric strength, but not functional capacity [54]. In conclusion, creatinine does not seem to significantly modulate CRF in individuals with COPD. Further exploration of varying doses and length of treatment of creatinine on muscle strength and endurance, as well as on FFM, is, however, warranted.

\subsection{Polyunsaturated Fatty Acid Supplementation in COPD}

Dietary intake of N-3 PUFA has been proposed to promote anti-inflammatory benefits in patients with COPD [55]. Despite these promising results, intake of N-3 PUFA has failed to increase CRF in individuals with COPD (moderate severity), but has augmented muscle function. An 8-week randomized placebo-controlled trial examining N-3 PUFA supplementation in patients undergoing inpatient PR failed to show an improvement on peak $\mathrm{VO}_{2}$ [38]. The N-3 PUFA supplement consisted of $340 \mathrm{mg}$ docosahexanoic acid (DHA) (22:6n-3), $700 \mathrm{mg}$ eicosapentanoic acid (EPA) (20:5n-3), $1200 \mathrm{mg}$ alpha-linolenic acid (ALA) (18:3n-3), $760 \mathrm{mg}$ gamma-linolenic acid (18:3n-6), and $400 \mathrm{mg}$ stearidonic acid (18:4n-3) [38]. The placebo supplement was isocaloric and contained a blend of $80 \%$ palm and $20 \%$ sunflower oils [38]. Submaximal exercise time, peak workload, and mechanical efficiency (ratio of $\mathrm{VO}_{2}$ to peak work load) were, however, increased in the N-3 PUFA group compared with placebo [38]. The authors also observed an increase in respiratory exchange ratio (RER) in the group under the $\mathrm{N}-3$ PUFA supplementation when compared with those receiving placebo, which they hypothesized may be due to an ability to go further into anaerobic metabolism, but without providing more information 
about potential mechanisms [38]. Thus, the impact of N-3 PUFA supplementation to improve CRF in COPD merits further study.

\subsection{Micronutrient Supplementation in COPD}

Malnutrition is commonly observed in patients with COPD and is associated with hypovitaminosis, especially vitamin D deficiency [56]. Although the precise role that vitamin D may exert on the pathophysiology of COPD is not completely understood, several studies have suggested involvement in airway impairment and exacerbated inflammatory response [57]. In addition, vitamin D deficiency may also be associated with impaired SM function, playing a potential role in CRF [42]. Indeed, patients with lower concentrations of vitamin D have reported shorter distance in the 6MWT than those with higher circulating content of this antioxidant [57]. Although these relationships infer promising results using vitamin D supplementation in COPD, a limited number of clinical trials have explored this possibility, and results obtained are conflicting. A randomized, double-blind, placebo-controlled trial in a very severe cohort of patients with COPD showed that supplementation with 100,000 IU of vitamin $\mathrm{D}$ for one year was ineffective to reduce pulmonary exacerbations [43]. A post-hoc subgroup analysis of the data, however, suggested that participants participating in PR and receiving vitamin D supplementation exhibited greater improvements in muscle strength of inspiratory muscles and overall oxygen uptake when compared to those not participating in PR [42].

Similarly, supplementation with vitamin B12, a complex involved in mitochondrial metabolism and exercise tolerance [58,59], has been explored in COPD with positive results. A randomized, double-blind clinical trial used PR in combination with 8 weeks of $500 \mathrm{mg}$ of daily B12 supplementation in subjects with moderate-to-severe COPD [44]. Although authors described discrete positive effects on exercise tolerance evaluated through CPET, no significant changes were observed in oxygen consumption between groups, with the exception of improved total exercise time [44]. The authors noted that small sample size and disparity in baseline physical activity between participants may have limited trial results [44]. Further studies are needed to elucidate the potential impact of vitamin supplementation alone or in combination with PR on CRF of individuals with COPD.

\subsection{Dietary Nitrate Supplementation in COPD}

Nitric oxide (NO) is a critical vasodilator involved in blood flow regulation and oxygen $\left(\mathrm{O}_{2}\right)$ delivery to SM [39]. Although airflow obstruction may be involved in exercise intolerance in COPD, other mechanisms, including vascular dysfunction and associated low NO bioavailability, play critical roles in this manifestation [39]. Dietary nitrates have the potential to increase NO, increasing the supply and delivery of $\mathrm{O}_{2}$ to the working SM, and thus improving CRF [39]. Multiple studies have described that beetroot juice, a major dietary source of nitrates, enhances NO synthesis, vascular function, and exercise capacity in healthy individuals [60-62]. Despite the compelling observations in multiple populations, results in COPD are unclear. Positive results have been described in eleven subjects with COPD (moderate-to-very severe) that consumed an acute dose of beetroot juice or placebo [39]. Three hours post-dose, nine participants exhibited an improved ISWT when compared with placebo [39]. Although the study was completed in a small and heterogeneous population, authors concluded that dietary nitrate supplementation abrogated exercise-related fatigue in patients with COPD [39]. Another study also described that an acute ingestion of beetroot juice mildly extends the time to fatigue during submaximal exercise in COPD (mild-to-moderate severity) [63]. Conversely, in a different study, after a 6-day trial of beetroot juice consumption, distance on the 6MWT did not improve [40]. Similar results were observed in another acute dietary nitrate supplementation intervention that described similar ESWT distance and time to fatigue between active and placebo in the same population [64]. Notably, longer supplementation with beetroot juice (8 days) showed similar results with no improvements in peak $\mathrm{VO}_{2}$ [41]. The authors surmised that dietary nitrate supplementation in COPD may be inconsistent due to the inter-subject variability in age, disease severity, and comorbidities. None of the above studies included PR or ET as part of the intervention. In addition, the authors also highlighted 
the multiple mechanisms of dysfunction contributing to reduced CRF in COPD that may also limit the response observed [41]. Other potential factors contributing to the disparity in results may be associated with medication. Beta 2 adrenergic receptor agonists, one of the most common treatments for COPD, are known to increase endothelial NO synthesis and may attenuate the potential effects of dietary nitrate supplementation [65]. In addition, other medications, including ACEi/ARBs, have been proposed as potential pharmacologic interventions that alter NO bioavailability [66], though other results conflict with this finding [67].

\subsection{Nutrition Support Supplementation in COPD}

Malnutrition further aggravates exercise intolerance in COPD. Specially, these individuals are at high risk for loss of SMM and the development of sarcopenia and cachexia [68]. Thus, the combination of calorically-rich supplement strategies with PR has been proposed to improve CRF in this population. Overall, nutritional support promotes an increase in weight gain, muscle strength, pulmonary function, exercise capacity, and overall quality of life in malnourished patients with COPD [69,70]. Respifor is a dietary supplement that affects CRF and body composition [45,50]. Respifor contains $60 \%$ carbohydrate, $20 \%$ fat, $20 \%$ protein, and provides 570 calories when taken orally three times a day [45,50]. Its effects on CRF and body composition have been studied as part of the INTERCOM trial in muscle-wasted patients (defined by unintentional weight loss or reduced FFM index $\left(\right.$ FFMI $=$ FFM kg/ht $\left.{ }^{2}\right)$ ) [50]. Thirty-nine patients were randomized to usual care or Respifor supplementation for a period of 4 months in combination with ET, proceeded by 20 months of active maintenance [50]. Active maintenance included nutrition supplementation, if still indicated, as well as less frequent visits with a dietitian and exercise physiologist to measure adherence [50]. After 4 months, the intervention group demonstrated a significant gain in FFMI, as well as an increase in functional capacity measured by 6MWT distance and peak watts achieved on cycle ergometer over the usual care group [50]. At 24 months, cycle ergometry was not repeated, but 6MWT distance was significantly reduced in the usual care group versus the intervention group, which remained stable from baseline, suggesting a protective effect of the supplement by preventing the decline in functional capacity [50]. Interestingly, an earlier randomized placebo-controlled trial examined an equal amount of Respifor supplementation in a group of patients referred for a 7-week PR program. This study found that while ISWT did not change in the overall cohort $\left(N=60\right.$ completed), when patients with a body mass index (BMI) $<19.0 \mathrm{~kg} / \mathrm{m}^{2}$ were excluded $(N=8)$, ISWT significantly increased in supplemented patients versus controls [45]. These conflicting results could possibly be due to the length of the PR, in combination with the supplementation intervention, which was significantly longer in the INTERCOM study $[45,50]$. In addition, weight gain was also significant only in the supplemented patients with BMI $>19 \mathrm{~kg} / \mathrm{m}^{2}$, but this was driven by an increase in FM [45]. Interestingly, previous studies with other nutritional supplements (i.e., beetroot juice) have also denoted a disparity between responders and non-responders based on BMI, inferring a potential role of adiposity that needs to be further explored [71]. Additionally, a study of 36 individuals with COPD (moderate-to-severe), who were less than $\leq 110 \%$ of ideal body weight, demonstrated benefit in a 12-week home-based PR and nutrition supplementation (200 calories, $55 \%$ carbohydrate, $20 \%$ fat, $25 \%$ protein incorporating whey peptides, N-3 PUFA consisting of $4 \mathrm{~g}$ ALA [18:3n-3], 800 mg DHA [22:6n-3], 1.2 g EPA [20:5n-3], and vitamins A, C, and E taken twice daily). The authors described improvements in 6MWT distance and weight, specifically FM, that increased significantly in the group receiving PR in combination with the supplement compared with the control [47]. Biomarkers of systemic inflammation, such as high-sensitivity C-Reactive Protein (CRP) and Tumor Necrosis Factor Alpha (TNF $\alpha$ ), also decreased significantly in patients receiving $\mathrm{PR}$ and nutritional supplement compared with the control. The authors attributed these results to the anti-inflammatory effects of whey peptide; however, such a hypothesis would clearly require further confirmatory studies [47]. Furthermore, as there was no exercise-only group in this study, it is difficult to separate the effects of supplementation versus that of PR [47]. Another study utilizing an energy-containing supplement in individuals with COPD and evidence of malnutrition (i.e., low FFMI, 
BMI, or evidence of weight loss) demonstrated that oral nutrition supplements ( $83 \%$ carbohydrate, $30 \%$ fat, $17 \%$ protein [no calorie amount given]) in combination with PR was not more effective than PR alone in increasing 6MWT or ISWT distance [49]. Patients with nutrition supplementation, in addition to PR, did increase weight and FFMI to a greater degree than PR alone [49]. Lastly, the NUTRAIN trial, a recent double-blind randomized controlled trial, looked at the effects of a supplement providing 188 calories, $60 \%$ carbohydrate, $20 \%$ fat, and $20 \%$ protein, and enriched with $N-3$ PUFA (consisting of $367.9 \mathrm{mg}$ ALA [18:3n-3], $118.5 \mathrm{mg}$ DHA [22:6n-3], and $248.8 \mathrm{mg}$ EPA [20:5n-3]), leucine, and vitamin D in individuals with COPD and low FFMI in addition to 4 months of PR [46]. Post-intervention, body weight and FM were significantly higher in patients taking supplement versus control, but 6MWT distance was not different [46]. Greater carbohydrate content mainly served to increase supplemented calories. Nonetheless, a greater caloric intake through higher content in fats has been proposed as a more beneficial approach for some patients with COPD, especially those with hypercapnia and severe shortness of breath [72-75]. The reason behind this recommendation relies on the metabolism of fats that produces less carbon dioxide $\left(\mathrm{CO}_{2}\right)$ per $\mathrm{O}_{2}$, resulting in a lower RER compared with carbohydrate metabolism, and therefore, will not increase $\mathrm{CO}_{2}$ content in hypercapnic patients. Despite these possible benefits, further studies are needed to determine if nutritional supplements rich in fats will improve CRF in patients with COPD.

\subsection{Summary of Nutrition Interventions in COPD}

In summary, while PR demonstrates a clear benefit for individuals with COPD, no effective adjunct nutrition strategy for enhancement of CRF has been identified at this time. While creatine and dietary nitrates are not likely a useful strategy for CRF enhancement [35-37,39-41], some trials with high energy supplements have shown a potential benefit $[45,47,50]$, while others have not $[46,49]$ (Table 1). Additionally, N-3 PUFA may have also demonstrated some benefit on enhancing exercise capacity, though a direct benefit on peak $\mathrm{VO}_{2}$ was not shown [38]. We also believe that future work should more clearly describe the ET component utilized in PR, the timing of the nutrient supplement in relation to exercise, and, when possible, utilizing objective biomarkers of nutrient consumption. Furthermore, considering the heterogeneity of COPD pathophysiology, we recommend that a greater description of the disease severity, including disease severity stage, medication, and comorbidities, as well as weight and muscle wasting status, may help elucidating which sub-group of patients with COPD may benefit the most from dietary supplementation.

Table 1. A summary of the lifestyle interventions with a nutrition component described in this paper in chronic obstructive pulmonary disease (COPD), heart failure (HF), sarcopenia, and frailty. As obesity focuses primarily on weight loss interventions, interventions have been summarized separately in Table 2.

\begin{tabular}{|c|c|c|c|c|}
\hline & Peak $\mathrm{VO}_{2}$ & $6 \mathrm{MWT}$ & ISWT & $400 \mathrm{~m}$ Walk \\
\hline \multicolumn{5}{|c|}{ COPD } \\
\hline Creatine [35-37] & $\leftrightarrow$ & $? ?$ & $\leftrightarrow$ & \\
\hline N-3 PUFA [38] & $\leftrightarrow$ & $? ?$ & $? ?$ & \\
\hline Vitamin D [43] & $? ?$ & $? ?$ & $? ?$ & \\
\hline Vitamin B12 [44] & $? ?$ & ?? & ?? & \\
\hline Dietary Nitrates $[39-41,63,64]$ & $\leftrightarrow$ & $\leftrightarrow$ & $\uparrow$ & \\
\hline Nutrition Support Supplements $[45-47,49,50]$ & $? ?$ & $\leftrightarrow$ & $\leftrightarrow$ & \\
\hline \multicolumn{5}{|c|}{ HFrEF } \\
\hline Multivitamin [76] & $? ?$ & $\leftrightarrow$ & & \\
\hline Essential AA [77-79] & $\uparrow$ & $\uparrow$ & & \\
\hline BCAA $[80]$ & $\leftrightarrow$ & $? ?$ & & \\
\hline L-Carnosine [81] & $\uparrow$ & $\uparrow$ & & \\
\hline Glutamine + N-3 PUFA [82] & $\leftrightarrow$ & $\leftrightarrow$ & & \\
\hline N-3 PUFA [83] & $\uparrow$ & $\leftrightarrow$ & & \\
\hline Nutrition Support Supplements [84] & $\leftrightarrow$ & $\uparrow$ & & \\
\hline Dietary Nitrates $[85,86]$ & $\leftrightarrow$ & ?? & & \\
\hline
\end{tabular}


Table 1. Cont.

\begin{tabular}{|c|c|c|c|c|}
\hline & Peak $\mathrm{VO}_{2}$ & 6 MWT & ISWT & $400 \mathrm{~m}$ Walk \\
\hline \multicolumn{5}{|c|}{ HFpEF } \\
\hline HCD [87] & $\uparrow \uparrow$ & $? ?$ & & \\
\hline UFA Supplementation $[88,89]$ & $? ?$ & ?? & & \\
\hline DASH Diet $[90,91]$ & ?? & $\uparrow$ & & \\
\hline Dietary Nitrates $[92,93]$ & $\leftrightarrow$ & ?? & & \\
\hline \multicolumn{5}{|c|}{ Sarcopenia and Frailty } \\
\hline Whey Protein [94] & ?? & ?? & & $\leftrightarrow$ \\
\hline Whey Protein + Vitamin D [95] & ?? & ?? & & $\leftrightarrow$ \\
\hline
\end{tabular}

HCD, Hypocaloric diet; peak VO2, peak oxygen consumption; 6MWT, six minute walk test; ISWT, incremental shuttle walking test; COPD, chronic obstructive pulmonary disease; $\mathrm{HFrEF}$, heart failure with reduced ejection fraction; HFpEF, heart failure with preserved ejection fraction; N-3 PUFA, omega 3 polyunsaturated fatty acids; AA, amino acids; BCAA, branch chain amino acids; UFA, unsaturated fatty acids; DASH, Dietary Approach to Stop Hypertension; $\uparrow$ Increase, $\leftrightarrow$ No Effect, ?? Lack of Data at this time.

Table 2. Comparison between diet, exercise, and diet and exercise combined in published randomized controlled trials. The combination of hypocaloric diet (HCD) and exercise training (ET) has demonstrated more consistent improvements in peak oxygen consumption $\left(\mathrm{VO}_{2}\right)$ than ET or diet alone [96-99].

\begin{tabular}{ccc}
\hline & Peak $\mathbf{V O}_{2}$ & Units \\
\hline & Diet & \\
\hline Villareal et al. (2011) & $\uparrow$ & $\mathrm{ml} / \mathrm{kg} / \mathrm{min}$ \\
Nicklas et al (2009) & $\uparrow$ & $\mathrm{ml} / \mathrm{kg} / \mathrm{min}$ \\
Straznicky et al (2010) & $\leftrightarrow$ & $\mathrm{ml} / \mathrm{kg} / \mathrm{FFM} / \mathrm{min}$ \\
Foster-Schubert et al (2012) & $\leftrightarrow$ & $\mathrm{L} / \mathrm{min}$ \\
\hline & Exercise & \\
\hline Villareal et al. (2011) & $\uparrow$ & $\mathrm{ml} / \mathrm{kg} / \mathrm{min}$ \\
Nicklas et al. (2009) & $\mathrm{N} / \mathrm{A}$ & $\mathrm{ml} / \mathrm{kg} / \mathrm{min}$ \\
Straznicky et al. (2010) & $\mathrm{N} / \mathrm{A}$ & $\mathrm{ml} / \mathrm{kg} \mathrm{FFM} / \mathrm{min}$ \\
Foster-Schubert et al. (2012) & $\uparrow$ & $\mathrm{L} / \mathrm{min}$ \\
\hline \multicolumn{1}{c}{ Diet and Exercise } & \\
\hline Villareal et al. (2011) & $\uparrow \uparrow$ & $\mathrm{ml} / \mathrm{kg} / \mathrm{min}$ \\
Nicklas et al. (2009) & $\uparrow \uparrow$ & $\mathrm{ml} / \mathrm{kg} / \mathrm{min}$ \\
Straznicky et al. (2010) & $\uparrow \uparrow$ & $\mathrm{ml} / \mathrm{kg} / \mathrm{Fm} / \mathrm{min}$ \\
Foster-Schubert et al. (2012) & $\uparrow$ & $\mathrm{L} / \mathrm{min}$ \\
\hline
\end{tabular}

HCD, Hypocaloric diet; peak VO2, peak oxygen consumption; $\mathrm{ml} / \mathrm{kg} / \mathrm{min}$, milliliters of oxygen consumption per minute; $\mathrm{ml} / \mathrm{kg}_{\mathrm{FFM}} / \mathrm{min}$, milliliters of oxygen consumption per kilogram fat free mass per minute; $\mathrm{L} / \mathrm{min}$, liters of oxygen consumption per minute; $\uparrow$ Increase from baseline, $\uparrow \uparrow$ Increase versus both exercise and diet intervention, $\leftrightarrow$ No effect seen

\section{Heart Failure}

The clinical syndrome of HF is characterized by reduced CRF accompanied by dyspnea and fatigue [2]. Low CRF is a significant risk for $\mathrm{HF}$, and improvements in peak $\mathrm{VO}_{2}$ through $\mathrm{ET}$ are associated with decreases in CVD and all-cause mortality, as well as HF hospitalizations [100,101]. A reduction in cardiac output is a major contributor to reduced CRF in HF patients, but individuals with HF also suffer malfunction throughout the oxygen transport chain in the form of pulmonary and SM abnormalities, as well as other exercise-limiting comorbidities such as obesity and anemia [2]. There are two major types of HF-HF with reduced ejection fraction (HFrEF) and HF with preserved ejection fraction (HFpEF). Although individuals with HFrEF and HFpEF both suffer from exercise intolerance, individuals with HFrEF may be more limited by central reductions in cardiac reserve, while those with HFpEF may be more limited by SM abnormalities in oxygen extraction and utilization [102], as well as other comorbidities such as obesity $[103,104]$. The majority of studies examining nutrition 
strategies to increase CRF have been performed in HFrEF patients, and there exists a major need to address the lack of therapies available to HFpEF patients.

Nutrition interventions to improve CRF in HFrEF patients have included micronutrient supplementation [76], amino acids (AA) [77-81], nutrition support supplementation [84], N-3 PUFA [82,83], and dietary nitrates [85,86].

\subsection{Micronutrient Supplementation in HFrEF}

Micronutrient supplementation was explored as a potential therapy to increase CRF, as patients with heart failure may be more susceptible to multiple deficiencies due low dietary intake, altered absorption, and pharmacologic treatments, and may have increased needs due to increased oxidative stress, as well as dysfunction of SMM and myocardial tissue [76]. In a double-blind, randomized controlled trial with 32 older adults ( $>70$ years) participants with HFrEF due to ischemic cardiomyopathy receiving a daily micronutrient supplement containing calcium, magnesium, zinc, copper, selenium, B-vitamins, vitamins A,C,D, and E, as well as co-enzyme Q10 or placebo for 9 months [76], patients receiving the supplement experienced positive cardiac remodeling compared to placebo, with reduced left ventricular (LV) end-diastolic and end-systolic volumes and improved LVEF measured by cardiac magnetic resonance imaging (MRI). There was no ET included as part of the intervention [76]. No changes in inflammatory biomarkers or 6MWT distance in supplemented patients versus controls were found [76]. Additionally, small trials in HFrEF patients have shown that thiamine supplementation improves LVEF and may also provide symptomatic improvements in these individuals; however, given the lack of good quality data, results should be interpreted cautiously [105].

\subsection{Amino Acid Supplementation in HFrEF}

Supplementation of multiple or individual AA have demonstrated mixed results on modulation of CRF in individuals with HFrEF. AA can be utilized as energy-producing substrates in the citric acid cycle, and SM of individuals with HF have demonstrated increased AA metabolism at rest. A group of 95 older ( $>65$ years of age) HFrEF patients with reduced exercise tolerance, defined as a peak $\mathrm{VO}_{2}<15 \mathrm{~mL} \cdot \mathrm{kg}^{-1} \cdot \mathrm{min}^{-1}$, was supplemented with $4 \mathrm{~g}$ of essential AA twice a day or an isocaloric placebo composed of carbohydrate in a 30-day randomized double-blinded control trial [78]. After 30 days, participants in the AA group demonstrated increased relative peak $\mathrm{VO}_{2}$ on cycle ergometer CPET versus placebo [78]. Similarly, it was demonstrated in another randomized control trial that 2 months of supplementation with $8 \mathrm{~g}$ of essential AA increased peak $\mathrm{VO}_{2}$ and $6 \mathrm{MWT}$ distance, as well as body weight in patients with adequate protein-energy intake at baseline and without depletion of SMM defined by reduced arm muscle area [79]. In a pilot-trial of $13 \mathrm{HFrEF}$ patients with dilated cardiomyopathy, a mix of essential and semi-essential AA was administered at the dose of $4 \mathrm{~g}$ twice daily for 3 months [77]. After 3 months, relative peak $\mathrm{VO}_{2}$ on cycle ergometer CPET was increased from baseline, as was $\mathrm{VO}_{2}$ at the anaerobic threshold. Distance on the 6MWT was also improved [77]. There was no change in echocardiographic parameters, but a trend in reduction of NT-proBNP was observed [77]. Not all AA supplements have proved successful however. In a randomized control trial of 66 individuals with HFrEF, subjects were assigned to either $5 \mathrm{~g}$ of branched chain AA (BCAA) twice a day plus resistance ET or resistance ET alone for 3 months [80]. Resistance ET sessions were performed for $1 \mathrm{~h}$ twice a week and in the supplementation group, $5 \mathrm{~g}$ of the BCAA was administered immediately prior to exercise [80]. An individualized, standard diet was prescribed to all participants, and the supplemented group was instructed to subtract $10 \mathrm{~g}$ of protein from their diet to account for the additional intake through the BCAA supplement [80]. At 3 months, there were increases in peak $\mathrm{VO}_{2}$ (estimated from metabolic equivalent of tasks [METs] achieved on the treadmill stress test) and muscular strength measured by handgrip dynamometer in both groups, with no differences between the groups [80]. Phase angle, a measure of impedance gathered by bioelectrical impedance analysis which helps characterize quality and quantity of soft tissue [106], also increased in both groups, without a difference between groups [80]. Dietary intake, including protein intake, measured 
by 24-h dietary recall was also not different between groups at 3 months [80]. The authors proposed that the pre-existing pro-inflammatory, catabolic state in patients with HF may have induced a state of malabsorption in which patients could not utilize the BCAA for energy-producing purposes in the citric acid cycle or anabolism [80]. In contrast, the aforementioned trials using essential AA have suggested that these supplements can in fact enhance CRF, making it likely that the supplements were absorbed and utilized by the body [77-79]. Only one of these trials utilized a biomarker to objectively measure intake (leucine), showing a significant increase in plasma leucine after supplementation [79]. Additionally, only one of the trials included ET as part of the intervention [80].

Levo-carnosine (L-carnosine), a dipeptide composed of beta-alanine and histidine, has also been examined for its effects on CRF. L-Carnosine is a multi-functional molecule that functions as an antioxidant and declines with aging, shown to be potentially cardio- and nephro-protective, and helps buffer lactic acid during physical exertion [81]. A randomized control trial of 50 individuals with HFrEF examined the effects of $500 \mathrm{mg}$ daily of L-carnosine versus standard care for 6 months [81]. There was no ET included as part of the intervention [81]. At 6 months, no within-group statistical changes were reported with regards to exercise variables, with the exception of the 6MWT, which was improved in the L-carnosine group, but not in the control group [81]. However, the changes in peak $\mathrm{VO}_{2}$ were significantly different between the L-carnosine group $(+1.1 \mathrm{~mL} / \mathrm{kg} / \mathrm{min})$ compared to the control, which, in fact, experienced a trend toward a reduction in peak $\mathrm{VO}_{2}(-1.4 \mathrm{~mL} / \mathrm{kg} / \mathrm{min})$. Similarly, the changes of $\mathrm{VO}_{2}$ at the anaerobic threshold, a measure of submaximal effort [2] and peak ET workload on cycle ergometer CPET, favored the L-carnosine-supplemented group versus control (Figure 1) [81]. Of note, no significant changes in echocardiographic parameters occurred [81]. Because there were no significant changes in the primary analysis of the study in the within-group analysis, the potential benefits described should be interpreted with caution, and clearly require further study in an appropriately powered randomized controlled trial.

The authors surmised that the observed positive effects of L-carnosine on CRF were very likely due to the $\mathrm{pH}$ buffering effect, which delayed muscular acidosis [81].

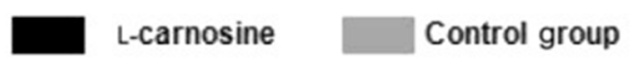

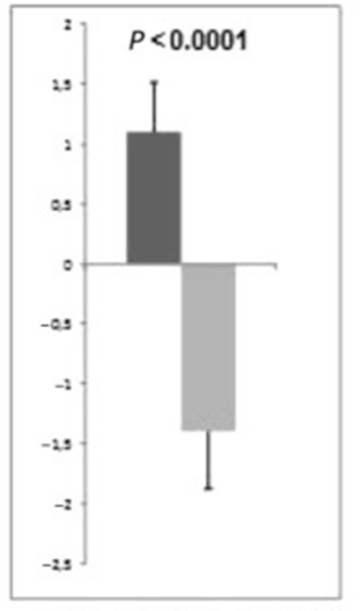

$\mathrm{VO}_{2}$ peak $(\mathrm{mL} \cdot \mathrm{kg} \cdot \mathrm{min})$

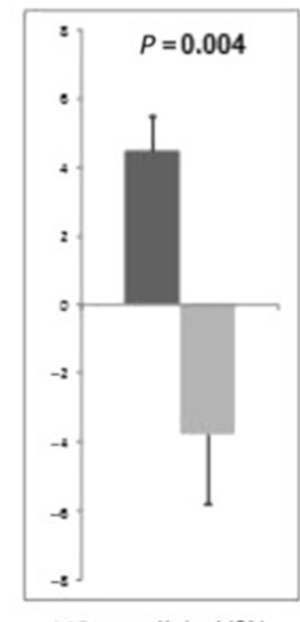

$\mathrm{VO}_{2}$ predicted $(\%)$

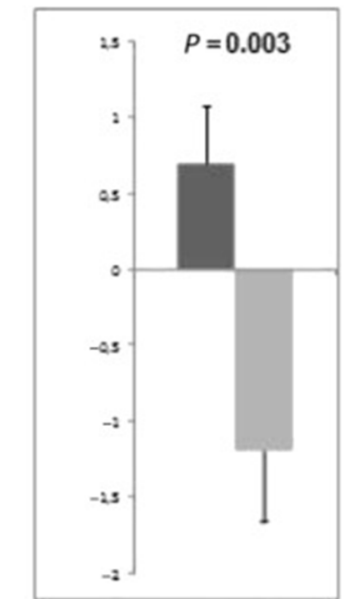

$\mathrm{VO}_{2}$ anaerobic thershold $(\mathrm{mL} \cdot \mathrm{kg} \cdot \mathrm{min})$

Figure 1. Six months of supplementation with $500 \mathrm{mg}$ L-Carnosine daily increased $\mathrm{VO}_{2}(\mathrm{~mL} / \mathrm{kg} / \mathrm{min})$, percent predicted peak $\mathrm{VO}_{2}(\%)$, and $\mathrm{VO}_{2}$ at the anaerobic threshold $(\mathrm{mL} / \mathrm{kg} / \mathrm{min})$ versus standard treatment in 50 patients with HFrEF. Used with permission by Lombardi et al. [81].

\subsection{Polyunsaturated Fatty Acid Supplementation in HFrEF}

Glutamine, an AA involved in the production of the endogenous antioxidant glutathione, as well as decreasing muscular proteolysis, has been combined with N-3 PUFA to examine the effects 
on CRF in HFrEF. In a double-blind, randomized placebo-controlled trial, 31 subjects with HFrEF were assigned to receive either a combination supplement of $6.5 \mathrm{~g}$ of $\mathrm{N}-3$ PUFA and $8 \mathrm{~g}$ of glutamine or an isocaloric placebo composed of safflower oil and milk powder for 3 months [82]. No ET was included as part of the intervention. Although LM increased in the active group upon dual-energy X-ray absorptiometry (DEXA) scan, there were no differences on exercise parameters on cycle ergometer CPET, 6MWT distance, measures of muscular strength, echocardiographic parameters, or SM biopsy [82]. In contrast, another trial of N-3 PUFA supplementation without glutamine demonstrated an increase in CRF with N-3 PUFA supplementation [83]. A randomized, double-blind placebo-controlled trial assigned 133 individuals with HFrEF of non-ischemic etiology to 12 months of placebo or N-3 PUFA supplementation, beginning with a 1 g gelatin capsule containing 850-882 mg N-3 PUFA capsules 5 times a day for the first month, decreasing to 2 daily capsules for the remaining 11 months [83]. There was no ET included as part of the intervention [83]. At the 12-month follow-up, LVEF was significantly increased, while LV diameters and volumes were significantly decreased in the N-3 PUFA-supplemented patients versus the placebo group [83]. In N-3 PUFA-supplemented patients, relative peak $\mathrm{VO}_{2}$, workload, and length of ET were increased relative to the placebo group [83]. Additionally, inflammatory biomarkers, including TNF $\alpha$ a, interleukin-6 (IL-6), and IL-1, were decreased significantly in supplemented patients versus placebo [83]. The authors attributed the increase in CRF to the observed increases in cardiac functionality, which they theorized was improved by multiple factors, including the reduction in inflammatory biomarkers, as well as improved contractile and endothelial functioning [83]. Interestingly, however, a decrease in diastolic function defined as an increased deceleration time was also observed in the supplemented subjects versus placebo [83].

\subsection{Nutrition Support Supplementation in HFrEF}

Cardiac cachexia, or the concomitant loss of lean mass (LM) and FM, in advanced HF patients is linked to poor prognosis $[27,107]$. Gaps in understanding continue to exist, but multiple mechanisms are likely at play, including high levels of inflammation, alterations in hunger/satiety signaling, changes in energy metabolism, as well as poor perfusion leading to malabsorption in the gut [107]. Though low intake alone is not causative, nutrition supplements high in calories and protein may be beneficial therapeutic options. A randomized, double-blind placebo-controlled pilot trial explored the value of a high-calorie, high-protein supplement in 29 subjects with HFrEF who had experienced an edema-free weight loss of $>7.5 \%$ over at least 6 months [84]. Subjects were then randomized 3:1 to receive the supplement, which supplied 600 calories and $20 \mathrm{~g}$ of protein, or placebo supplying 12 calories with a similar taste and texture for a 6-week period [84]. There was no ET included as part of the intervention [84]. All subjects were instructed to continue their normal diet. At the 6-week end of study visit, Patients in the supplementation group did gain a significant amount of weight, mostly FM on DEXA scan, which was maintained at the 18-week follow-up visit [84]. On DEXA, LM was increased in the supplemented patients at 6 weeks, but this change was not maintained at 18 weeks [84]. While 6MWT distance increased in supplemented patients, relative peak $\mathrm{VO}_{2}$ did not increase upon CPET, and LVEF was not increased upon echocardiogram analysis [84]. TNF $\alpha$ was significantly reduced in supplemented patients [84]. Although relative peak $\mathrm{VO}_{2}$ did not increase in supplemented subjects versus placebo, suggesting no changes in CRF, the increases in FM and 6MWT distance combined with the decrease in TNF $\alpha$ suggest potential beneficial effects on other important health status indicators in $\mathrm{HF}$, which requires further investigation [108].

\subsection{Summary of Nutrition Interventions in HFrEF}

The supplementation of essential AA, N-3 PUFA, and L-carnosine may increase CRF in individuals with HFrEF [77-79,81,83] (Table 1). Future work should aim to study the effect of these supplements on CRF over the long term with varied dosing to elucidate the dosing needed to increase CRF. Additionally, biomarkers of intake should be utilized in all future studies to objectively measure intake of the supplements. 


\subsection{Hypocaloric Diets in HFpEF}

HFpEF is a heterogenous syndrome characterized by high filling pressures and diastolic abnormalities in the setting of an LVEF $\geq 50 \%$, which currently lacks evidence-based therapies to reduce morbidity and mortality [109-111]. Higher BMI and insulin resistance increase risk for HFpEF more than HFrEF, and over $80 \%$ of patients with HFpEF are also overweight and obese [26,112]. This has resulted in the suggestion of a HFpEF-obesity phenotype, although this is controversial, with the opposing argument being that HFpEF and obesity are comorbid conditions with separate CRF abnormalities [103,104,113-115]. Lower CRF is linked to worsened prognosis in HFpEF, and ET has proven effective in increasing CRF $[116,117]$. A trial of 100 patients with obesity and HFpEF randomized subjects into a 20-week $2 \times 2$ factorial trial consisting of ET, hypocaloric diet (HCD), ET and HCD combined, and attention control groups [87]. ET was individualized and mostly centered on a walking program performed for $1 \mathrm{~h}, 3$ times a week [87]. The HCD was provided by the center's metabolic kitchen and individualized to the subject's energy needs, with a 350 calorie deficit for individuals randomized to exercise and caloric restriction and a 400 calorie deficit for those assigned to caloric restriction alone [87]. The attention control received a phone call every 2 weeks from investigators [87]. While both exercise and HCD groups individually demonstrated an increase in relative peak $\mathrm{VO}_{2}$ at 20 weeks, the effect of the combined group was additive and resulted in a greater increase in relative peak $\mathrm{VO}_{2}$ [87]. Absolute peak $\mathrm{VO}_{2}$, not adjusted for body weight, was increased with exercise and unchanged by HCD [87]. Exercise and HCD together also created an additive beneficial effect on peak workload and exercise time, as well as weight loss, which was 10\% for HCD and exercise combined, 7\% for HCD alone, 3\% for exercise alone, and 1\% for the control group [87]. On DEXA scan, HCD resulted in loss of LM, FM, and FM percent of body weight, but exercise resulted in loss of FM alone, therefore preserving LM [87]. High sensitivity CRP was reduced by HCD but not exercise, and reduction was correlated with degree of weight lost [87]. Subjects were highly adherent to both exercise $(84 \%$ sessions attended) and diet interventions (99\% from recorded food logs) [87]. Because only small improvements on cardiac mass were found, the authors attributed the increases in exercise capacity to noncardiac peripheral adaptations [87]. This study demonstrated that, particularly in individuals with obesity and HFpEF, HCD and exercise result in larger improvements in CRF than either intervention alone. Furthermore, the increase in relative peak $\mathrm{VO}_{2}$ and lack of decrease in absolute peak $\mathrm{VO}_{2}$ seen in this trial demonstrate that despite the obesity paradox in HF, which holds that obese patients may have improved survival over their normal and underweight peers [118], the combination of HCD and exercise in individuals with obesity and HFpEF may, in fact, improve CRF. Whether such changes result in improve clinical outcomes requires further study.

\subsection{Unsaturated Fatty Acid Supplementation in HFpEF}

Although a low-fat diet has been long favored in the prevention and treatment of CVD, a diet high in unsaturated fatty acids (UFA) may hold far more cardioprotective benefit [119]. A cross-sectional analysis of 23 subjects with HFpEF and obesity demonstrated that consumption of mono- and polyunsaturated fatty acids (MUFA and PUFA, respectively) was positively correlated with relative peak $\mathrm{VO}_{2}$ [88]. This relationship was strengthened when these fatty acids were combined and expressed as total consumption of UFA in grams, as well as in percentage of total calories [88]. Saturated fatty acids were initially also associated with peak $\mathrm{VO}_{2}$, but the relationship disappeared upon multivariate analysis when both UFA and saturated fatty acids were included [88]. Dietary sugars were also analyzed and found to be inversely correlated with peak $\mathrm{VO}_{2}$ [88]. Additionally, UFA consumption was associated with better diastolic function on echocardiogram, as well as greater FFM percentage of body weight and a better FFM to FM ratio on bioelectrical impedance analysis [88]. In the UFA-Preserved pilot trial, nine subjects with HFpEF and obesity supplemented their diet with UFA-rich foods (including extra-virgin olive oil, canola oil, unsalted or lightly salted mixed nuts, seeds, avocado, and fatty fish) for 12 weeks with baseline dietary counseling and weekly phone call reinforcement by a dietitian [89]. There was no ET included as part of the intervention [89]. After 12 weeks, subjects had a significant 
increase in UFA plasma biomarkers and reported increased intake of UFA on 24-h dietary recall (Figure 2A) [89]. Subjects demonstrated a trend towards improving their peak $\mathrm{VO}_{2}$ on treadmill CPET, which was associated, though non-significantly, with changes in plasma UFA, as well as MUFA and PUFA individually (Figure 2B) [89]. Whether these beneficial effects translate into improvements in clinical outcomes, as well as CRF in a larger sample size, is unknown and requires further work. Currently, the follow-up randomized controlled trial (UFA-Preserved2) is ongoing (NCT03966755) and examining the effect of daily UFA supplementation versus standard of care dietary recommendations (controlling sodium and saturated fatty acids intake) in a randomized, crossover format in 30 subjects with HFpEF and concomitant obesity.
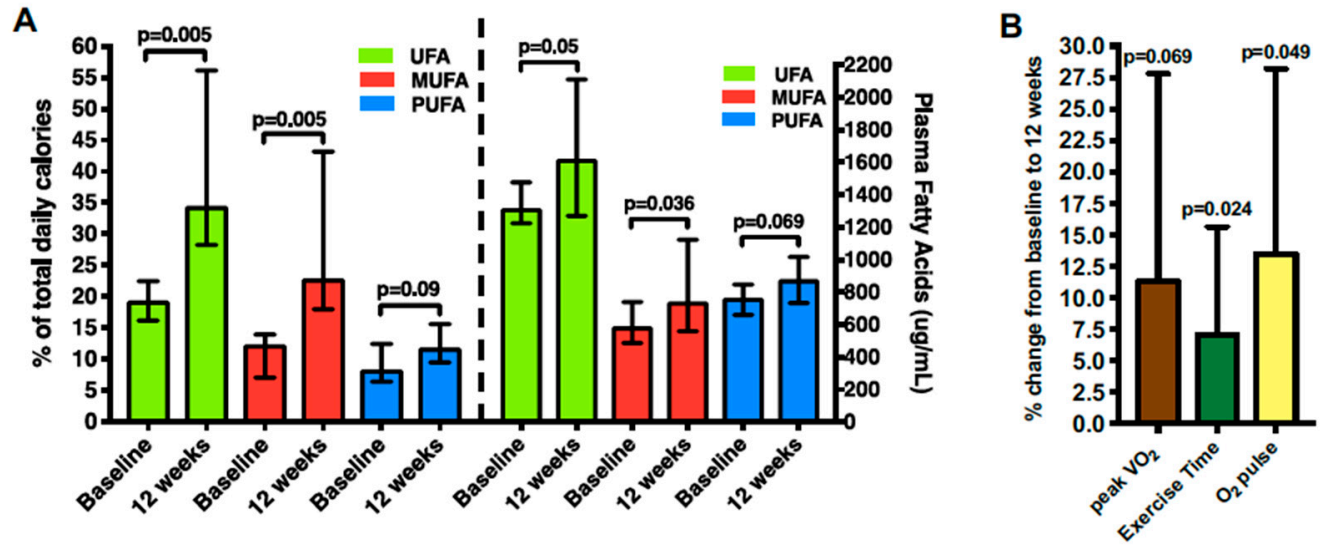

Figure 2. (A) Demonstrates increases from baseline to 12-week follow-up in UFA, MUFA, and PUFA expressed in percent total daily calories, as well as plasma fatty acids $(\mu \mathrm{g} / \mathrm{mL})$ in nine HFpEF subjects who supplemented dietary UFA daily for 12 weeks as part of the UFA-Preserved pilot trial. (B) Demonstrates trend towards increase in Peak $\mathrm{VO}_{2}(\mathrm{~mL} / \mathrm{kg} / \mathrm{min})$, exercise time, and $\mathrm{O}_{2}$ pulse (mL/beat) from baseline to 12-week follow-up in the UFA-Preserved pilot trial. Used with permission by Carbone et al. [89]. UFA, unsaturated fatty acids; MUFA, monounsaturated fatty acids; PUFA, polyunsaturated fatty acids; Peak $\mathrm{VO}_{2}$, peak oxygen consumption; $\mathrm{O}_{2}$, oxygen.

\subsection{Dietary Approaches to Stop Hypertension in HFpEF}

Hypertension is a frequent comorbidity in $\mathrm{HFpEF}$, and a significant portion of individuals with HFpEF may be sensitive to dietary sodium. In a pilot trial of 13 subjects with HFpEF, 21 days of the Dietary Approaches to Stop Hypertension (DASH) diet combined with sodium restriction resulted in an improved distance on the 6MWT, as well as reduced clinic and 24-h (BP) measurements [90]. No ET was included in this intervention [90]. Carotid-femoral pulse wave velocity also significantly improved, and the authors attributed the improvement in 6MWT distance to this reduction in arterial stiffness [90]. Notably, all food was provided for patients during this trial, which likely aided greatly in compliance to the intervention [90]. In 48 patients with HFpEF or HFrEF, 3 months of DASH diet also resulted in improved 6MWT distance versus usual care, although the intervention group failed to reduced sodium consumption [91]. No ET was included as part of the intervention [91]. Endothelial function measured by large and small artery elasticity was not improved in the intervention group versus the control [91]. In this study, the authors argued that the improvement in 6MWT distance may be due more to cardiac and autonomic factors, rather than improvements in endothelial function [91].

\subsection{Dietary Nitrate Supplementation in HFpEF}

Dietary nitrates, which are reduced to NO in the plasma after gut absorption, have been proposed as a mechanism to increase CRF in individuals with HFpEF by decreasing BP and improving SM perfusion. A randomized, placebo-controlled pilot trial examining the effect of dietary nitrates, in addition to aerobic ET, in subjects with HFpEF showed no benefit when compared to placebo on peak $\mathrm{VO}_{2}$ [92]. The authors suggested that this may have been related to inadequate dosing; however, a 
recent trial of inhaled nitrates without ET also failed to increase peak $\mathrm{VO}_{2}$ in subjects with HFpEF [93]. Dietary nitrate supplementation has also resulted in mixed effects on CRF in small pilot trials of subjects with HFrEF without ET [85,86]. Currently, the INABLE-Training trial (NCT02713126) is combining higher dosing of oral nitrates with a cardiac rehabilitation (CR) program for 12 weeks in a double-blind, randomized placebo-controlled trial of patients with HFpEF on a primary outcome of peak $\mathrm{VO}_{2}$. The study is testing the hypothesis that oral sodium nitrate combined with $\mathrm{CR}$ results in greater improvements in peak $\mathrm{VO}_{2}$ than $\mathrm{CR}$ alone.

\subsection{Summary of Nutrition Interventions in HFpEF}

Evidence-based therapies are urgently needed for HFpEF. With the prevalence of obesity in this population, the combination of ET and HCD is very promising, but would need to be implemented in larger scale, multicenter trials [87] (Table 1). The sodium-restricted DASH diet also offers an appealing treatment for the common comorbidity of hypertension among HFpEF patients and larger, multicenter trials should be implemented $[90,91]$ (Table 1). A home delivery program of the sodium-restricted DASH diet was shown recently to trend towards a reduction in HF 30-day readmissions, demonstrating the possibility that improvements seen in the 6MWT may translate to improved outcomes [120].

\section{Obesity}

Individuals who are less physically active are more likely to become obese, and those who are obese are more likely to avoid PA [121-124]. Obesity negatively impacts CRF through central and peripheral changes in structure and function, such as remodeling of the heart, restrictive action of excess mass on ventilation, endothelial and mitochondrial dysfunction in the SM, and challenge to the biomechanics of PA [125]. Individuals with obesity, however, do not necessarily have reduced CRF, and "fat but fit" individuals with higher CRF may have attenuated risk for all-cause and CVD mortality, a contradiction known as the obesity paradox $[125,126]$. Peak $\mathrm{VO}_{2}$ is often reported corrected for body mass (relative peak $\mathrm{VO}_{2}$ ), which results in an automatically lowered appearance for individuals with obesity versus their normal weight peers, but CRF may, in fact, be normal or mildly reduced when reported in absolute terms [125]. Nevertheless, obesity remains a major risk factor for numerous noncommunicable disease states, and weight loss is recommended to lower this risk [127]. Weight loss interventions focused solely on diet, however, often result in loss of LM, as well as FM, and it is important to examine the effects this may have on CRF [96-98]. This is especially important as weight regain often occurs and the individual may regain to their former weight with more FM and less LM, which is perhaps even more detrimental to their CRF.

\subsection{Hypocaloric Diets in Obesity}

Multiple studies have examined the effects of HCD alone versus HCD combined with ET in individuals with obesity on cardiometabolic risk factors, including CRF $[96-99,128]$. Though the studies differed in design, studies that compared HCD alone versus HCD combined with ET found that relative [96,97], relative to LM [128], and sometimes absolute [99] peak $\mathrm{VO}_{2}$ increased more in the HCD and ET combination groups versus the HCD alone. One study was unclear on whether an absolute or relative peak $\mathrm{VO}_{2}$ was being reported, but peak $\mathrm{VO}_{2}$ was still reported as increased more in the HCD and ET group versus HCD alone [98]. Body weight and FM loss was usually similar in the HCD and ET groups versus HCD alone [96-98,128], but this was not always the case [99]. HCD only groups often experienced a greater loss of LM or LM as a percent of body weight [96-99], but not always [97]. Loss of waist circumference, reflecting visceral adiposity, was sometimes greater in the ET and HCD groups versus HCD alone [99,128], but not always [97].

\subsection{Macronutrient Composition of Hypocaloric Diets in Obesity}

Although recent studies have suggested that macronutrient composition of HCD does not affect the degree of weight lost [18], the question remains of whether it affects CRF. One randomized study 
examined the effects of an extremely low carbohydrate versus a moderately low-fat diet in 60 men and women who were overweight or obese after 8 weeks of a 52-week intervention [129]. Subjects also had abdominal obesity and at least one metabolic syndrome risk factor, as defined by the AHA [129]. The diets were equally hypocaloric and the low carbohydrate HCD consisted of 35\% energy from protein, $61 \%$ from fat, and $4 \%$ from carbohydrate, while the low-fat HCD had $24 \%$ energy from protein, $30 \%$ from fat, and $46 \%$ from carbohydrate [129]. There was no ET component to the intervention [129]. Participates met with a dietitian and turned in semi-quantitative food records every 2 weeks, and compliance to the low carbohydrate diet was measured with levels of plasma ketones [129]. At the end of the 8 weeks, men lost more weight, as well as FM, measured by DEXA on the low carbohydrate HCD, while a difference in weight and FM loss between the two HCD was not observed in women [129]. On treadmill CPET, absolute peak $\mathrm{VO}_{2}$ was reduced and relative peak $\mathrm{VO}_{2}$ remained the same in both groups, with no effect of HCD [129]. For the 43 participants who completed the entire 52-week period of the study, both groups had similar reductions in weight and FM loss [130]. Absolute peak $\mathrm{VO}_{2}$ remained decreased from baseline, but relative peak $\mathrm{VO}_{2}$ increased in both groups, without differences between groups [130]. Another randomized study examined altering the protein composition of a low-fat HCD in 56 overweight or obese men for 12 weeks [131]. There was no ET included as part of the intervention [131]. The diets were moderately hypocaloric and the high protein HCD consisted of $35 \%$ energy from protein, $40 \%$ from carbohydrate, and $25 \%$ energy from fat, while the low protein HCD provided 17\% energy from protein, 58\% energy from carbohydrate, and 25\% energy from fat [131]. Participants met with a dietitian and turned in semi-quantitative food records every 2 weeks during the intervention [131]. Weight and FFM loss were not different between the two groups, but there was a non-significant trend towards greater FM loss in the high protein group [131]. On treadmill CPET, absolute peak $\mathrm{VO}_{2}$ did not change, but relative peak $\mathrm{VO}_{2}$ increased, with no between $\mathrm{HCD}$ group differences [131].

\subsection{Summary of Nutrition Interventions in Obesity}

In determining optimum plan for weight loss in obesity, it appears that it may be slightly more beneficial to add exercise to a HCD in terms of reduction in visceral adiposity $[99,128]$ and preventing a loss of LM [96-99]. Total weight and FM loss do not seem to differ, regardless of whether or not a exercise component is added to a HCD [96-98,128]. Effects on absolute peak $\mathrm{VO}_{2}$ are mixed $[99,129,130]$, but relative peak $\mathrm{VO}_{2}$ is likely to stay the same or increase $[96,97,128,130,131]$. Macronutrient composition of the HCD does not seem to matter on weight, $\mathrm{LM}$, or FM loss, or peak/absolute $\mathrm{VO}_{2}$ change, but more research is clearly needed to definitively answer this important question [129-131]. Overall, short-term weight loss is likely not harmful and may be beneficial to CRF; however, longer term follow-up is needed to determine the potential difference in outcomes in those who regain compared to those who do not regain weight post-intervention.

\section{Sarcopenia and Frailty}

Sarcopenia is a reduction in SM strength accompanied by either a loss of mass or quality while FM is preserved [132]. When low physical performance accompanies these characteristics, sarcopenia is considered severe [132]. Sarcopenia affects $5-20 \%$ of the population above 60 and up to $50 \%$ of individuals over 80 years of age [27]. Individuals with sarcopenia have a reduced CRF compared to their non-sarcopenic peers, especially in the presence of high FM, a condition known as sarcopenic obesity [133-136]. Furthermore, in individuals with HF, sarcopenia may be even more detrimental to CRF and quality of life than cachexia [135]. Frailty overlaps heavily with the physical manifestations of sarcopenia, but encompasses a broader range of geriatric decline that also includes cognitive and social deterioration associated with adverse outcomes [132]. 


\subsection{Nutrition Interventions in Sarcopenia and Frailty}

Most nutrition interventions in individuals with sarcopenia and frailty have included physical performance measures which attempt to gauge the effect of both SM and nervous system function on locomotion rather than CRF. These measures include the short physical performance battery (SPPB), timed-up and go test, gait speed, and occasionally the $400 \mathrm{~m}$ walk. The $400 \mathrm{~m}$ walk, like the 6MWT or ISWT, attempts to estimate CRF without the expense, trained personnel, and time required for CPET [137]. Many nutrients have been proposed to address the key physical components (lack of muscle strength, mass, quality, low physical performance) present in sarcopenia, including increased protein intake, creatine, Leucine, $\beta$-hydroxy- $\beta$ - methylbutyrate (HMB), vitamin D, and N-3 PUFA [138]. As studies remain heterogenous and large clinical trials are still lacking, no firm recommendations regarding nutrition interventions for sarcopenia and frailty currently exist, though essential AA and HMB have shown an effect on SMM and function [138,139].

\subsection{Dietary Patterns in Sarcopenia and Frailty}

Outside of individual nutrients, healthy dietary patterns may help to lessen the severity or delay onset of physical performance and CRF decline in older adults. In a cross-sectional analysis of 380 Spanish adults aged 55-80, higher adherence to a traditional Mediterranean dietary pattern was associated with greater walking distance on the 6MWT, while higher adherence to a Western dietary pattern was associated with a lower 6MWT distance [140]. In 117 individuals with T2DM, those over 75 years of age and in the highest tertile of adherence to the Mediterranean Diet demonstrated greater 6MWT and 10-min walk test distances than those less adherent [141].

\subsection{Protein Supplementation in Sarcopenia and Frailty}

Currently, there are few nutrition interventions in older adults with physical characteristics of sarcopenia or frailty that include CRF measurements. In 80 older adults aged 70-85 with a low SPPB score $(<10)$, a 6-month randomized, double-blind placebo-controlled trial of whey protein was conducted in combination with regular resistance ET [94]. Participants received $40 \mathrm{~g}$ of whey protein split into two doses per day or an isocaloric amount of maltodextrin [94]. Adherence to the nutrition intervention was measured by an objective biomarker, para-aminobenzoic acid, which was added to the supplements [94]. The supervised resistance ET program took place 3 times a week [94]. Whey protein has been theorized to be an ideal supplement to promote SM anabolism as it has a high proportion of essential AA [94]. Participants improved in strength in all muscle groups measured and gained some LM; however, there were no differences between groups and there was no significant change in $400 \mathrm{~m}$ walk distance from baseline [94]. Another recent trial randomized 149 participants over 70 years of age with low vitamin D status and SPPB score $(\leq 9)$ to a ready-to-drink supplement containing whey protein and vitamin D versus a low calorie, non-nutritive beverage for 6 months [95]. Participants also underwent a PA program 3 days a week for the duration of the trial [95]. The supplement contained 150 calories, $20 \mathrm{~g}$ of whey protein, and 800 international units of vitamin D, while the identical placebo contained 30 calories [95]. While the supplement group experienced greater declines in intramuscular fat measured by computed tomography than the placebo group, both groups had similar decreases in total body FM on DEXA scan and gains in muscular strength [95]. There were also improvements in both groups in the $400 \mathrm{~m}$ walk test, but no between-group differences were observed [142].

\subsection{Summary of Nutrition Interventions in Sarcopenia and Frailty}

Although individuals with sarcopenia have a low CRF compared to their nonsarcopenic peers [133-136], there are a lack of trials currently that demonstrate efficacy of nutrition interventions in altering CRF in this population, despite increases in CRF at the lower end of the spectrum having the greatest effect on health outcomes [1] (Table 1). Future trials should also focus on recruiting subjects with sarcopenia defined by population-appropriate guidelines [132,143]. 


\section{Future Directions}

As recognition of low CRF as a risk factor for morbidity and mortality grows, more knowledge is accrued about the pathogenesis of exercise intolerance in different disease states and CRF is more widely used as an outcome measure. A wide variety of disease states such as chronic kidney disease (CKD), cancer, non-alcoholic steatohepatitis, atrial fibrillation, and pulmonary hypertension are now recognized to be associated with reduced CRF, and all have a role for nutrition therapy that may assist in increasing CRF and improving outcomes [144-149].

Exercise testing in subjects with stage 3-4 CKD has revealed a reduced CRF with altered central and peripheral responses to exercise compared to healthy age matched controls [144]. Furthermore, in subjects with stage 2-4 CKD who performed the 6MWT, those who walked a distance below $350 \mathrm{~m}$ versus those above that threshold had a significantly decreased risk of survival [145]. In terms of dietary changes and their effects on CRF in individuals with CKD, little is known. A recent trial randomized 111 subjects with CKD with overweight/obesity in a $2 \times 2$ factorial trial to caloric restriction, ET, both caloric restriction and ET, or usual care [150]. Mean glomerular filtration rate was $41 \pm 18.6 \mathrm{mg} / \mathrm{mL}$ per $1.73 \mathrm{~m}^{2}$ [150]. After 4 months, there were no evident effects of the interventions on peak $\mathrm{VO}_{2}$ [150]. Further research is greatly needed regarding the effects of nutrition on CRF in CKD and a wealth of dietary targets exist [151].

Individuals with cancer and cancer survivors are another group more recently recognized to have a reduced CRF. Aging-related declines in CRF, coupled with the effects of cancer treatments (radiation, chemotherapy, hormone therapy etc.), can lead to significantly reduced exercise tolerance [146]. Several recent trials in cancer survivors have found that lifestyle interventions combining dietary counseling and PA/ET have been able to improve relative peak $\mathrm{VO}_{2}$ compared to usual care [152,153] and in comparison to subjects' baseline [154]. It is difficult to distinguish the effects of ET from nutrition-related improvements, as trials thus far have not included separate ET and diet intervention groups. This is particularly relevant, as these trials reported CRF as relative peak $\mathrm{VO}_{2}$ and also reported decreases in weight, in which dietary intervention may play a larger role [152-154].

\section{Limitations}

Limitations of trials aimed at examining the effects of nutrition on CRF are notable and widespread in many nutrition research studies. Dosing of nutrition supplements, diet design, and approaches to nutrition counseling differ widely between studies [155]. Trials are often small and obviously difficulties in blinding exist, especially in regard to dietary patterns [155]. Measuring adherence to the dietary intervention is often much more challenging than measuring pharmaceutical adherence. Developing standards of practice and design in nutrition research remains an ongoing issue. However, increasing recognition and calls to action to increase the rigor of nutrition research will hopefully result in trials that more definitively provide guidelines for evidence-based practice, including in the use of nutrition therapy to increase CRF [155].

\section{Conclusions}

Nutrition therapy offers a promising role in increasing CRF in multiple populations with exercise limitations, including COPD, HF, obesity, sarcopenia, and frailty. As disease states with reduced CRF continue to be defined, nutrition intervention trials in these populations should include measurements of CRF. Additionally, the potential effect of dietary patterns such as DASH and Mediterranean diets on CRF should be studied in a randomized format in noncommunicable disease states where they have shown improvements in other surrogate measures of health. Standardized approaches and larger trials are clearly needed to determine which therapies may be the most efficacious and result in improvements in clinical outcomes.

Author Contributions: H.E.B.: writing—original draft preparation. P.R.-M., M.G.D.B., A.A., C.J.L., and S.C.: writing-review and editing. 
Funding: Paula Rodriguez-Miguelez (18CDA34110323) and Salvatore Carbone (19CDA34660318) were both supported by AHA Career Development Awards.

Conflicts of Interest: The authors declare no conflicts of interest.

\section{References}

1. Ross, R.; Blair, S.N.; Arena, R.; Church, T.S.; Després, J.P.; Franklin, B.A.; Haskell, W.L.; Kaminsky, L.A.; Levine, B.D.; Lavie, C.J.; et al. Importance of Assessing Cardiorespiratory Fitness in Clinical Practice: A Case for Fitness as a Clinical Vital Sign: A Scientific Statement from the American Heart Association. Circulation 2016, 134, e653-e699. [CrossRef]

2. Del Buono, M.G.; Arena, R.; Borlaug, B.A.; Carbone, S.; Canada, J.M.; Kirkman, D.L.; Garten, R.; Rodriguez-Miguelez, P.; Guazzi, M.; Lavie, C.J.; et al. Exercise Intolerance in Patients with Heart Failure: JACC State-of-the-Art Review. J. Am. Coll. Cardiol. 2019, 73, 2209-2225. [CrossRef]

3. Mandsager, K.; Harb, S.; Cremer, P.; Phelan, D.; Nissen, S.E.; Jaber, W. Association of Cardiorespiratory Fitness with Long-term Mortality Among Adults Undergoing Exercise Treadmill Testing. JAMA Netw. Open 2018, 1, e183605. [CrossRef] [PubMed]

4. Harber, M.P.; Kaminsky, L.A.; Arena, R.; Blair, S.N.; Franklin, B.A.; Myers, J.; Ross, R. Impact of Cardiorespiratory Fitness on All-Cause and Disease-Specific Mortality: Advances Since 2009. Prog. Cardiovasc. Dis. 2017, 60, 11-20. [CrossRef] [PubMed]

5. Sawada, S.S.; Lee, I.-M.; Naito, H.; Kakigi, R.; Goto, S.; Kanazawa, M.; Okamoto, T.; Tsukamoto, K.; Muto, T.; Tanaka, H.; et al. Cardiorespiratory fitness, body mass index, and cancer mortality: A cohort study of Japanese men. BMC Public Health 2014, 14, 1012. [CrossRef] [PubMed]

6. Robsahm, T.E.; Falk, R.S.; Heir, T.; Sandvik, L.; Vos, L.; Erikssen, J.E.; Tretli, S. Measured cardiorespiratory fitness and self-reported physical activity: Associations with cancer risk and death in a long-term prospective cohort study. Cancer Med. 2016, 5, 2136-2144. [CrossRef] [PubMed]

7. Kokkinos, P.; Myers, J.; Faselis, C.; Panagiotakos, D.B.; Doumas, M.; Pittaras, A.; Manolis, A.; Kokkinos, J.P.; Karasik, P.; Greenberg, M.; et al. Exercise capacity and mortality in older men: A 20-year follow-up study. Circulation 2010, 122, 790-797. [CrossRef] [PubMed]

8. Kaminsky, L.A.; Imboden, M.T.; Arena, R.; Myers, J. Reference Standards for Cardiorespiratory Fitness Measured with Cardiopulmonary Exercise Testing Using Cycle Ergometry: Data from the Fitness Registry and the Importance of Exercise National Database (FRIEND) Registry. Mayo Clin. Proc. 2017, 92, $228-233$. [CrossRef]

9. Hallal, P.C.; Andersen, L.B.; Bull, F.C.; Guthold, R.; Haskell, W.; Ekelund, U. Global physical activity levels: Surveillance progress, pitfalls, and prospects. Lancet 2012, 380, 247-257. [CrossRef]

10. Barlow, C.E.; DeFina, L.F.; Radford, N.B.; Berry, J.D.; Cooper, K.H.; Haskell, W.L.; Jones, L.W.; Lakoski, S.G. Cardiorespiratory Fitness and Long-Term Survival in "Low-Risk" Adults. J. Am. Heart Assoc. 2012, 1, e001354. [CrossRef]

11. Fletcher, G.F.; Ades, P.A.; Kligfield, P.; Arena, R.; Balady, G.J.; Bittner, V.A.; Coke, L.A.; Fleg, J.L.; Forman, D.E.; Gerber, T.C.; et al. Exercise Standards for Testing and Training. Circulation 2013, 128, 873-934. [CrossRef] [PubMed]

12. Lin, X.; Zhang, X.; Guo, J.; Roberts, C.K.; McKenzie, S.; Wu, W.C.; Liu, S.; Song, Y. Effects of Exercise Training on Cardiorespiratory Fitness and Biomarkers of Cardiometabolic Health: A Systematic Review and Meta-Analysis of Randomized Controlled Trials. J. Am. Heart Assoc. 2015, 4, e002014. [CrossRef] [PubMed]

13. O'Connor, C.M.; Whellan, D.J.; Lee, K.L.; Keteyian, S.J.; Cooper, L.S.; Ellis, S.J.; Leifer, E.S.; Kraus, W.E.; Kitzman, D.W.; Blumenthal, J.A.; et al. HF-ACTION Investigators, for the Efficacy and Safety of Exercise Training in Patients with Chronic Heart Failure: HF-ACTION Randomized Controlled Trial. JAMA 2009, 301, 1439-1450. [CrossRef] [PubMed]

14. Lavie, C.J.; Carbone, S.; Kachur, S.; O’Keefe, E.L.; Elagizi, A. Effects of Physical Activity, Exercise, and Fitness on Obesity-Related Morbidity and Mortality. Curr. Sports Med. Rep. 2019, 18, 292-298. [CrossRef]

15. Lavie, C.J.; Ozemek, C.; Carbone, S.; Katzmarzyk, P.T.; Blair, S.N. Sedentary Behavior, Exercise, and Cardiovascular Health. Circ. Res. 2019, 124, 799-815. [CrossRef]

16. Caspersen, C.J.; Powell, K.E.; Christenson, G.M. Physical activity, exercise, and physical fitness: Definitions and distinctions for health-related research. Public Health Rep. 1985, 100, 126-131. 
17. Abbate, A.; Van Tassell, B.W.; Canada, J.M.; Dixon, D.L.; Arena, R.A.; Biondi-Zoccai, G. Pharmacologic and surgical interventions to improve functional capacity in heart failure. Heart Fail. Clin. 2015, 11, 117-124. [CrossRef]

18. Gardner, C.D.; Trepanowski, J.F.; Del Gobbo, L.C.; Hauser, M.E.; Rigdon, J.; Ioannidis, J.P.A.; Desai, M.; King, A.C. Effect of Low-Fat vs Low-Carbohydrate Diet on 12-Month Weight Loss in Overweight Adults and the Association With Genotype Pattern or Insulin Secretion: The DIETFITS Randomized Clinical Trial. JAMA 2018, 319, 667-679. [CrossRef]

19. Aragon, A.A.; Schoenfeld, B.J.; Wildman, R.; Kleiner, S.; VanDusseldorp, T.; Taylor, L.; Earnest, C.P.; Arciero, P.J.; Wilborn, C.; Kalman, D.S.; et al. International society of sports nutrition position stand: Diets and body composition. J. Int. Soc. Sports Nutr. 2017, 14, 16. [CrossRef]

20. Saneei, P.; Salehi-Abargouei, A.; Esmaillzadeh, A.; Azadbakht, L. Influence of Dietary Approaches to Stop Hypertension (DASH) diet on blood pressure: A systematic review and meta-analysis on randomized controlled trials. Nutr. Metab. Cardiovasc. Dis. 2014, 24, 1253-1261. [CrossRef]

21. Eckel, R.H.; Jakicic, J.M.; Ard, J.D.; de Jesus, J.M.; Houston Miller, N.; Hubbard, V.S.; Lee, I.-M.; Lichtenstein, A.H.; Loria, C.M.; Millen, B.E.; et al. 2013 AHA/ACC guideline on lifestyle management to reduce cardiovascular risk: A report of the American College of Cardiology/American Heart Association Task Force on Practice Guidelines. Circulation 2014, 129, S76-S99. [CrossRef] [PubMed]

22. Medina-Remón, A.; Casas, R.; Tressserra-Rimbau, A.; Ros, E.; Martínez-González, M.A.; Fitó, M.; Corella, D.; Salas-Salvadó, J.; Lamuela-Raventos, R.M.; Estruch, R. Polyphenol intake from a Mediterranean diet decreases inflammatory biomarkers related to atherosclerosis: A substudy of the PREDIMED trial. Br. J. Clin. Pharmacol. 2017, 83, 114-128. [CrossRef] [PubMed]

23. Diabetes Prevention Program Research Group. 10-year follow-up of diabetes incidence and weight loss in the Diabetes Prevention Program Outcomes Study. Lancet 2009, 374, 1677-1686. [CrossRef]

24. Estruch, R.; Ros, E.; Salas-Salvadó, J.; Covas, M.-I.; Corella, D.; Arós, F.; Gómez-Gracia, E.; Ruiz-Gutiérrez, V.; Fiol, M.; Lapetra, J.; et al. Primary Prevention of Cardiovascular Disease with a Mediterranean Diet Supplemented with Extra-Virgin Olive Oil or Nuts. N. Engl. J. Med. 2018, 378, e34. [CrossRef] [PubMed]

25. Chlebowski, R.T.; Anderson, G.L.; Manson, J.E.; Prentice, R.L.; Aragaki, A.K.; Snetselaar, L.; Beresford, S.A.; Kuller, L.H.; Johnson, K.; Lane, D.; et al. Low-Fat Dietary Pattern and Cancer Mortality in the Women's Health Initiative (WHI) Randomized Controlled Trial. JNCI Cancer Spectr. 2019, 2. [CrossRef] [PubMed]

26. Carbone, S.; Lavie, C.J.; Arena, R. Obesity and Heart Failure: Focus on the Obesity Paradox. Mayo Clin. Proc. 2017, 92, 266-279. [CrossRef]

27. Carbone, S.; Billingsley, H.E.; Rodriguez-Miguelez, P.; Kirkman, D.L.; Garten, R.; Franco, R.L.; Lee, D.; Lavie, C.J. Lean Mass Abnormalities in Heart Failure: The Role of Sarcopenia, Sarcopenic Obesity, and Cachexia. Curr. Probl. Cardiol. 2019, S0146-S2806. [CrossRef]

28. Cote, C.G.; Pinto-Plata, V.; Kasprzyk, K.; Dordelly, L.J.; Celli, B.R. The 6-Min Walk Distance, Peak Oxygen Uptake, and Mortality in COPD. Chest 2007, 132, 1778-1785. [CrossRef]

29. Rochester, C.L.; Vogiatzis, I.; Holland, A.E.; Lareau, S.C.; Marciniuk, D.D.; Puhan, M.A.; Spruit, M.A.; Masefield, S.; Casaburi, R.; Clini, E.M.; et al. An Official American Thoracic Society/European Respiratory Society Policy Statement: Enhancing Implementation, Use, and Delivery of Pulmonary Rehabilitation. Am. J. Respir. Crit. Care Med. 2015, 192, 1373-1386. [CrossRef]

30. Spruit, M.A.; Singh, S.J.; Garvey, C.; ZuWallack, R.; Nici, L.; Rochester, C.; Hill, K.; Holland, A.E.; Lareau, S.C.; Man, W.D.-C.; et al. An Official American Thoracic Society/European Respiratory Society Statement: Key Concepts and Advances in Pulmonary Rehabilitation. Am. J. Respir. Crit. Care Med. 2013, 188, e13-e64. [CrossRef]

31. Polkey, M.I.; Spruit, M.A.; Edwards, L.D.; Watkins, M.L.; Pinto-Plata, V.; Vestbo, J.; Calverley, P.M.A.; Tal-Singer, R.; Agustí, A.; Bakke, P.S.; et al. Six-Minute-Walk Test in Chronic Obstructive Pulmonary Disease. Am. J. Respir. Crit. Care Med. 2013, 187, 382-386. [CrossRef]

32. Hernandes, N.A.; Wouters, E.F.M.; Meijer, K.; Annegarn, J.; Pitta, F.; Spruit, M.A. Reproducibility of 6-minute walking test in patients with COPD. Eur. Respir. J. 2011, 38, 261-267. [CrossRef] [PubMed]

33. Singh, S.J.; Puhan, M.A.; Andrianopoulos, V.; Hernandes, N.A.; Mitchell, K.E.; Hill, C.J.; Lee, A.L.; Camillo, C.A.; Troosters, T.; Spruit, M.A.; et al. An official systematic review of the European Respiratory Society/American Thoracic Society: Measurement properties of field walking tests in chronic respiratory disease. Eur. Respir. J. 2014, 44, 1447-1478. [CrossRef] [PubMed] 
34. Jaitovich, A.; Barreiro, E. Skeletal Muscle Dysfunction in Chronic Obstructive Pulmonary Disease. What We Know and Can Do for Our Patients. Am. J. Respir. Crit. Care Med. 2018, 198, 175-186. [CrossRef] [PubMed]

35. Deacon, S.J.; Vincent, E.E.; Greenhaff, P.L.; Fox, J.; Steiner, M.C.; Singh, S.J.; Morgan, M.D. Randomized controlled trial of dietary creatine as an adjunct therapy to physical training in chronic obstructive pulmonary disease. Am. J. Respir. Crit. Care Med. 2008, 178, 233-239. [CrossRef]

36. Fuld, J.P.; Kilduff, L.P.; Neder, J.A.; Pitsiladis, Y.; Lean ME, J.; Ward, S.A.; Cotton, M.M. Creatine supplementation during pulmonary rehabilitation in chronic obstructive pulmonary disease. Thorax 2005, 60, 531-537. [CrossRef]

37. Faager, G.; Soderlund, K.; Skold, C.M.; Rundgren, S.; Tollback, A.; Jakobsson, P. Creatine supplementation and physical training in patients with COPD: A double blind, placebo-controlled study. Int. J. Chron. Obstruct. Pulmon. Dis. 2006, 1, 445-453. [CrossRef]

38. Broekhuizen, R.; Wouters, E.F.M.; Creutzberg, E.C.; Weling-Scheepers, C.A.P.M.; Schols, A.M.W.J. Polyunsaturated fatty acids improve exercise capacity in chronic obstructive pulmonary disease. Thorax 2005, 60, 376-382. [CrossRef]

39. Kerley, C.P.; Cahill, K.; Bolger, K.; McGowan, A.; Burke, C.; Faul, J.; Cormican, L. Dietary nitrate supplementation in COPD: An acute, double-blind, randomized, placebo-controlled, crossover trial Nitric Oxide 2015, 44, 105-111. [CrossRef]

40. Friis, A.L.; Steenholt, C.B.; Løkke, A.; Hansen, M. Dietary beetroot juice-effects on physical performance in COPD patients: A randomized controlled crossover trial. Int. J. Chron. Obstruct. Pulmon. Dis. 2017, 12, 1765-1773. [CrossRef]

41. Behnia, M.; Wheatley, C.M.; Avolio, A.; Johnson, B.D. Influence of dietary nitrate supplementation on lung function and exercise gas exchange in COPD patients. Nitric Oxide 2018, 76, 53-61. [CrossRef] [PubMed]

42. Hornikx, M.; Van Remoortel, H.; Lehouck, A.; Mathieu, C.; Maes, K.; Gayan-Ramirez, G.; Decramer, M.; Troosters, T.; Janssens, W. Vitamin D supplementation during rehabilitation in COPD: A secondary analysis of a randomized trial. Respir. Res. 2012, 13, 84. [CrossRef] [PubMed]

43. Lehouck, A.; Mathieu, C.; Carremans, C.; Baeke, F.; Verhaegen, J.; Van Eldere, J.; Decallonne, B.; Bouillon, R.; Decramer, M.; Janssens, W. High doses of vitamin D to reduce exacerbations in chronic obstructive pulmonary disease: A randomized trial. Ann. Intern. Med. 2012, 156, 105-114. [CrossRef] [PubMed]

44. Paulin, F.V.; Zagatto, A.M.; Chiappa, G.R.; Muller, P.T. Addition of vitamin B12 to exercise training improves cycle ergometer endurance in advanced COPD patients: A randomized and controlled study. Respir. Med. 2017, 122, 23-29. [CrossRef] [PubMed]

45. Steiner, M.C.; Barton, R.L.; Singh, S.J.; Morgan MD, L. Nutritional enhancement of exercise performance in chronic obstructive pulmonary disease: A randomised controlled trial. Thorax 2003, 58, 745-751. [CrossRef] [PubMed]

46. van de Bool, C.; Rutten EP, A.; van Helvoort, A.; Franssen, F.M.E.; Wouters, E.F.M.; Schols, A.M.W.J. A randomized clinical trial investigating the efficacy of targeted nutrition as adjunct to exercise training in COPD. J. Cachexia. Sarcopenia Muscle 2017, 8, 748-758. [CrossRef]

47. Sugawara, K.; Takahashi, H.; Kashiwagura, T.; Yamada, K.; Yanagida, S.; Homma, M.; Dairiki, K.; Sasaki, H.; Kawagoshi, A.; Satake, M.; et al. Effect of anti-inflammatory supplementation with whey peptide and exercise therapy in patients with COPD. Respir. Med. 2012, 106, 1526-1534. [CrossRef]

48. Sugawara, K.; Takahashi, H.; Kasai, C.; Kiyokawa, N.; Watanabe, T.; Fujii, S.; Kashiwagura, T.; Honma, M.; Satake, M.; Shioya, T. Effects of nutritional supplementation combined with low-intensity exercise in malnourished patients with COPD. Respir. Med. 2010, 104, 1883-1889. [CrossRef]

49. Gurgun, A.; Deniz, S.; Argin, M.; Karapolat, H. Effects of nutritional supplementation combined with conventional pulmonary rehabilitation in muscle-wasted chronic obstructive pulmonary disease: A prospective, randomized and controlled study. Respirology 2013, 18, 495-500. [CrossRef]

50. van Wetering, C.R.; Hoogendoorn, M.; Broekhuizen, R.; Geraerts-Keeris, G.J.W.; De Munck, D.R.A.J.; Rutten-van Molken, M.P.M.H.; Schols, A.M.W.J. Efficacy and costs of nutritional rehabilitation in muscle-wasted patients with chronic obstructive pulmonary disease in a community-based setting: A prespecified subgroup analysis of the INTERCOM trial. J. Am. Med. Dir. Assoc. 2010, 11, 179-187. [CrossRef]

51. Greenhaff, P.L. Creatine and its application as an ergogenic aid. Int. J. Sport Nutr. 1995, 5, S100-S110. [CrossRef] [PubMed] 
52. Fiaccadori, E.; Del Canale, S.; Vitali, P.; Coffrini, E.; Ronda, N.; Guariglia, A. Skeletal muscle energetics, acid-base equilibrium and lactate metabolism in patients with severe hypercapnia and hypoxemia. Chest 1987, 92, 883-887. [CrossRef] [PubMed]

53. Carbone, S.; Popovic, D.; Lavie, C.J.; Arena, R. Obesity, body composition and cardiorespiratory fitness in heart failure with preserved ejection fraction. Future Cardiol. 2017, 13, 451-463. [CrossRef] [PubMed]

54. Brose, A.; Parise, G.; Tarnopolsky, M.A. Creatine supplementation enhances isometric strength and body composition improvements following strength exercise training in older adults. J. Gerontol. A Biol. Sci. Med. Sci. 2003, 58, 11-19. [CrossRef] [PubMed]

55. de Batlle, J.; Sauleda, J.; Balcells, E.; Gomez, F.P.; Mendez, M.; Rodriguez, E.; Barreiro, E.; Ferrer, J.J.; Romieu, I.; Gea, J.; et al. Association between Omega3 and Omega6 fatty acid intakes and serum inflammatory markers in COPD. J. Nutr. Biochem. 2012, 23, 817-821. [CrossRef]

56. Fernández-Lahera, J.; Romera, D.; Gómez Mendieta, A.; Martínez Verdasco, A.; Fernández-Bujarrabal, J.; Santiago, A.; Alcolea, S.; Martínez-Abad, Y.; Prados, C.; Villasante, C.; et al. Prevalence of vitamin D deficiency in patients with chronic obstructive pulmonary disease. Eur. Respir. J. 2015, 46, PA3977.

57. Jung, J.Y.; Kim, Y.S.; Kim, S.K.; Kim, H.Y.; Oh, Y.M.; Lee, S.M.; Seo, J.B.; Lee, S.-D. Relationship of vitamin D status with lung function and exercise capacity in COPD. Respirology 2015, 20, 782-789. [CrossRef]

58. Veeranki, S.; Winchester, L.J.; Tyagi, S.C. Hyperhomocysteinemia associated skeletal muscle weakness involves mitochondrial dysfunction and epigenetic modifications. Biochim. Biophys. Acta 2015, 1852, 732-741. [CrossRef]

59. Kuo, H.-K.; Liao, K.-C.; Leveille, S.G.; Bean, J.F.; Yen, C.-J.; Chen, J.-H.; Yu, Y.-H.; Tai, T.-Y. Relationship of homocysteine levels to quadriceps strength, gait speed, and late-life disability in older adults. J. Gerontol. A Biol. Sci. Med. Sci. 2007, 62, 434-439. [CrossRef]

60. Breese, B.C.; McNarry, M.A.; Marwood, S.; Blackwell, J.R.; Bailey, S.J.; Jones, A.M. Beetroot juice supplementation speeds $\mathrm{O}_{2}$ uptake kinetics and improves exercise tolerance during severe-intensity exercise initiated from an elevated metabolic rate. Am. J. Physiol. Regul. Integr. Comp. Physiol. 2013, 305, R1441-R1450. [CrossRef]

61. Lansley, K.E.; Winyard, P.G.; Fulford, J.; Vanhatalo, A.; Bailey, S.J.; Blackwell, J.R.; DiMenna, F.J.; Gilchrist, M.; Benjamin, N.; Jones, A.M. Dietary nitrate supplementation reduces the $\mathrm{O}_{2}$ cost of walking and running: A placebo-controlled study. J. Appl. Physiol. 2011, 110, 591-600. [CrossRef] [PubMed]

62. Bailey, S.J.; Winyard, P.; Vanhatalo, A.; Blackwell, J.R.; Dimenna, F.J.; Wilkerson, D.P.; Tarr, J.; Benjamin, N.; Jones, A.M. Dietary nitrate supplementation reduces the $\mathrm{O}_{2}$ cost of low-intensity exercise and enhances tolerance to high-intensity exercise in humans. J. Appl. Physiol. 2009, 107, 1144-1155. [CrossRef] [PubMed]

63. Berry, M.J.; Justus, N.W.; Hauser, J.I.; Case, A.H.; Helms, C.C.; Basu, S.; Rogers, Z.; Lewis, M.T.; Miller, G.D. Dietary nitrate supplementation improves exercise performance and decreases blood pressure in COPD patients. Nitric Oxide 2015, 48, 22-30. [CrossRef] [PubMed]

64. Leong, P.; Basham, J.E.; Yong, T.; Chazan, A.; Finlay, P.; Barnes, S.; Bardin, P.G.; Campbell, D. A double blind randomized placebo control crossover trial on the effect of dietary nitrate supplementation on exercise tolerance in stable moderate chronic obstructive pulmonary disease. BMC Pulm. Med. 2015, 15, 52. [CrossRef]

65. Wang, Y.X.; Poon, K.S.; Randall, D.J.; Pang, C.C. Endothelium-derived nitric oxide partially mediates salbutamol-induced vasodilatations. Eur. J. Pharmacol. 1993, 250, 335-340. [CrossRef]

66. Ceconi, C.; Fox, K.M.; Remme, W.J.; Simoons, M.L.; Bertrand, M.; Parrinello, G.; Kluft, C.; Blann, A.; Cokkinos, D.; Ferrari, R. ACE inhibition with perindopril and endothelial function. Results of a substudy of the EUROPA study: PERTINENT. Cardiovasc. Res. 2007, 73, 237-246. [CrossRef]

67. Cacciatore, F.; Bruzzese, G.; Vitale, D.F.; Liguori, A.; de Nigris, F.; Fiorito, C.; Infante, T.; Donatelli, F.; Minucci, P.B.; Ignarro, L.J.; et al. Effects of ACE inhibition on circulating endothelial progenitor cells, vascular damage, and oxidative stress in hypertensive patients. Eur. J. Clin. Pharmacol. 2011, 67, 877-883. [CrossRef]

68. van de Bool, C.; Steiner, M.C.; Schols, A.M.W.J. Nutritional targets to enhance exercise performance in chronic obstructive pulmonary disease. Curr. Opin. Clin. Nutr. Metab. Care 2012, 15, 553-560. [CrossRef]

69. Ferreira, I.M.; Brooks, D.; White, J.; Goldstein, R. Nutritional supplementation for stable chronic obstructive pulmonary disease. Cochrane Database Syst. Rev. 2012, 12, CD000998. [CrossRef]

70. Collins, P.F.; Elia, M.; Stratton, R.J. Nutritional support and functional capacity in chronic obstructive pulmonary disease: A systematic review and meta-analysis. Respirology 2013, 18, 616-629. [CrossRef] 
71. Shepherd, A.I.; Wilkerson, D.P.; Dobson, L.; Kelly, J.; Winyard, P.G.; Jones, A.M.; Benjamin, N.; Shore, A.C.; Gilchrist, M. The effect of dietary nitrate supplementation on the oxygen cost of cycling, walking performance and resting blood pressure in individuals with chronic obstructive pulmonary disease: A double blind placebo controlled, randomised control trial. Nitric Oxide Biol. Chem. 2015, 48, 31-37. [CrossRef] [PubMed]

72. Cai, B.; Zhu, Y.; Ma, Y.; Xu, Z.; Zao, Y.; Wang, J.; Lin, Y.; Comer, G.M. Effect of supplementing a high-fat, low-carbohydrate enteral formula in COPD patients. Nutrition 2003, 19, 229-232. [CrossRef]

73. al-Saady, N.M.; Blackmore, C.M.; Bennett, E.D. High fat, low carbohydrate, enteral feeding lowers $\mathrm{PaCO}_{2}$ and reduces the period of ventilation in artificially ventilated patients. Intensive Care Med. 1989, 15, 290-295. [CrossRef] [PubMed]

74. Angelillo, V.A.; Bedi, S.; Durfee, D.; Dahl, J.; Patterson, A.J.; O’Donohue, W.J.J. Effects of low and high carbohydrate feedings in ambulatory patients with chronic obstructive pulmonary disease and chronic hypercapnia. Ann. Intern. Med. 1985, 103, 883-885. [CrossRef]

75. Frankfort, J.D.; Fischer, C.E.; Stansbury, D.W.; McArthur, D.L.; Brown, S.E.; Light, R.W. Effects of high- and low-carbohydrate meals on maximum exercise performance in chronic airflow obstruction. Chest 1991, 100, 792-795. [CrossRef]

76. Witte, K.K.A.; Nikitin, N.P.; Parker, A.C.; von Haehling, S.; Volk, H.-D.; Anker, S.D.; Clark, A.L.; Cleland, J.G.F. The effect of micronutrient supplementation on quality-of-life and left ventricular function in elderly patients with chronic heart failure. Eur. Heart J. 2005, 26, 2238-2244. [CrossRef]

77. Lombardi, C.; Carubelli, V.; Lazzarini, V.; Vizzardi, E.; Quinzani, F.; Guidetti, F.; Rovetta, R.; Nodari, S.; Gheorghiade, M.; Metra, M. Effects of oral amino Acid supplements on functional capacity in patients with chronic heart failure. Clin. Med. Insights. Cardiol. 2014, 8, 39-44. [CrossRef]

78. Aquilani, R.; Viglio, S.; Iadarola, P.; Opasich, C.; Testa, A.; Dioguardi, F.S.; Pasini, E. Oral Amino Acid Supplements Improve Exercise Capacities in Elderly Patients with Chronic Heart Failure. Am. J. Cardiol. 2008, 101, S104-S110. [CrossRef]

79. Aquilani, R.; Opasich, C.; Gualco, A.; Verri, M.; Testa, A.; Pasini, E.; Viglio, S.; Iadarola, P.; Pastoris, O.; Dossena, M.; et al. Adequate energy-protein intake is not enough to improve nutritional and metabolic status in muscle-depleted patients with chronic heart failure. Eur. J. Heart Fail. 2008, 10, 1127-1135. [CrossRef]

80. Pineda-Juárez, J.A.; Sánchez-Ortiz, N.A.; Castillo-Martínez, L.; Orea-Tejeda, A.; Cervantes-Gaytán, R.; Keirns-Davis, C.; Pérez-Ocampo, C.; Quiroz-Bautista, K.; Tenorio-Dupont, M.; Ronquillo-Martínez, A. Changes in body composition in heart failure patients after a resistance exercise program and branched chain amino acid supplementation. Clin. Nutr. 2016, 35, 41-47. [CrossRef]

81. Lombardi, C.; Carubelli, V.; Lazzarini, V.; Vizzardi, E.; Bordonali, T.; Ciccarese, C.; Castrini, A.I.; Dei Cas, A.; Nodari, S.; Metra, M. Effects of oral administration of orodispersible levo-carnosine on quality of life and exercise performance in patients with chronic heart failure. Nutrition 2015, 31, 72-78. [CrossRef] [PubMed]

82. Wu, C.; Kato, T.S.; Ji, R.; Zizola, C.; Brunjes, D.L.; Deng, Y.; Akashi, H.; Armstrong, H.F.; Kennel, P.J.; Thomas, T.; et al. Supplementation of 1-Alanyl-1-Glutamine and Fish Oil Improves Body Composition and Quality of Life in Patients With Chronic Heart Failure. Circ. Hear. Fail. 2015, 8, 1077-1087. [CrossRef] [PubMed]

83. Nodari, S.; Triggiani, M.; Campia, U.; Manerba, A.; Milesi, G.; Cesana, B.M.; Gheorghiade, M.; Dei Cas, L. Effects of $n-3$ polyunsaturated fatty acids on left ventricular function and functional capacity in patients with dilated cardiomyopathy. J. Am. Coll. Cardiol. 2011, 57, 870-879. [CrossRef]

84. Rozentryt, P.; von Haehling, S.; Lainscak, M.; Nowak, J.U.; Kalantar-Zadeh, K.; Polonski, L.; Anker, S.D. The effects of a high-caloric protein-rich oral nutritional supplement in patients with chronic heart failure and cachexia on quality of life, body composition, and inflammation markers: A randomized, double-blind pilot study. J. Cachexia. Sarcopenia Muscle 2010, 1, 35-42. [CrossRef] [PubMed]

85. Hirai, D.M.; Zelt, J.T.; Jones, J.H.; Castanhas, L.G.; Bentley, R.F.; Earle, W.; Staples, P.; Tschakovsky, M.E.; McCans, J.; O'Donnell, D.E.; et al. Dietary nitrate supplementation and exercise tolerance in patients with heart failure with reduced ejection fraction. Am. J. Physiol. Integr. Comp. Physiol. 2016, 312, R13-R22. [CrossRef]

86. Coggan, A.R.; Broadstreet, S.R.; Mahmood, K.; Mikhalkova, D.; Madigan, M.; Bole, I.; Park, S.; Leibowitz, J.L.; Kadkhodayan, A.; Thomas, D.P.; et al. Dietary Nitrate Increases VO2peak and Performance but Does Not Alter Ventilation or Efficiency in Patients With Heart Failure With Reduced Ejection Fraction. J. Card. Fail. 2018, 24, 65-73. [CrossRef] 
87. Kitzman, D.W.; Brubaker, P.; Morgan, T.; Haykowsky, M.; Hundley, G.; Kraus, W.E.; Eggebeen, J.; Nicklas, B.J. Effect of Caloric Restriction or Aerobic Exercise Training on Peak Oxygen Consumption and Quality of Life in Obese Older Patients with Heart Failure with Preserved Ejection Fraction: A Randomized Clinical Trial. JAMA 2016, 315, 36-46. [CrossRef]

88. Carbone, S.; Canada, J.M.; Buckley, L.F.; Trankle, C.R.; Billingsley, H.E.; Dixon, D.L.; Mauro, A.G.; Dessie, S.; Kadariya, D.; Mezzaroma, E.; et al. Dietary Fat, Sugar Consumption, and Cardiorespiratory Fitness in Patients with Heart Failure with Preserved Ejection Fraction. JACC Basic Transl. Sci. 2017, 2, 513-525. [CrossRef]

89. Carbone, S.; Billingsley, H.E.; Canada, J.M.; Kadariya, D.; Medina De Chazal, H.; Rotelli, B.; Potere, N.; Paudel, B.; Markley, R.; Dixon, D.L.; et al. Unsaturated Fatty Acids to Improve Cardiorespiratory Fitness in Patients with Obesity and HFpEF- The UFA PRESERVED Pilot Study. JACC Basic Transl. Sci. 2019, 4, 563-565. [CrossRef]

90. Hummel, S.L.; Seymour, E.M.; Brook, R.D.; Kolias, T.J.; Sheth, S.S.; Rosenblum, H.R.; Wells, J.M.; Weder, A.B. Low-Sodium Dietary Approaches to Stop Hypertension Diet Reduces Blood Pressure, Arterial Stiffness, and Oxidative Stress in Hypertensive Heart Failure with Preserved Ejection Fraction. Hypertension 2012, 60, 1200-1206. [CrossRef]

91. Rifai, L.; Pisano, C.; Hayden, J.; Sulo, S.; Silver, M.A. Impact of the DASH diet on endothelial function, exercise capacity, and quality of life in patients with heart failure. Proc. (Bayl. Univ. Med. Cent). 2015, 28, 151-156. [CrossRef] [PubMed]

92. Shaltout, H.A.; Eggebeen, J.; Marsh, A.P.; Brubaker, P.H.; Laurienti, P.J.; Burdette, J.H.; Basu, S.; Morgan, A.; Dos Santos, P.C.; Norris, J.L.; et al. Effects of supervised exercise and dietary nitrate in older adults with controlled hypertension and/or heart failure with preserved ejection fraction. Nitric Oxide 2017, 69, 78-90. [CrossRef] [PubMed]

93. Borlaug, B.A.; Anstrom, K.J.; Lewis, G.D.; Shah, S.J.; Levine, J.A.; Koepp, G.A.; Givertz, M.M.; Felker, G.M.; LeWinter, M.M.; Mann, D.L.; et al. Effect of Inorganic Nitrite vs Placebo on Exercise Capacity Among Patients with Heart Failure with Preserved Ejection Fraction: The INDIE-HFpEF Randomized Clinical Trial. JAMA 2018, 320, 1764-1773. [CrossRef] [PubMed]

94. Chalé, A.; Cloutier, G.J.; Hau, C.; Phillips, E.M.; Dallal, G.E.; Fielding, R.A. Efficacy of Whey Protein Supplementation on Resistance Exercise-Induced Changes in Lean Mass, Muscle Strength, and Physical Function in Mobility-Limited Older Adults. Journals Gerontol. Ser. A 2012, 68, 682-690. [CrossRef]

95. Englund, D.A.; Kirn, D.R.; Koochek, A.; Zhu, H.; Travison, T.G.; Reid, K.F.; von Berens, A.; Melin, M.; Cederholm, T.; Gustafsson, T.; et al. Nutritional Supplementation with Physical Activity Improves Muscle Composition in Mobility-Limited Older Adults, The VIVE2 Study: A Randomized, Double-Blind, Placebo-Controlled Trial. J. Gerontol. A Biol. Sci. Med. Sci. 2017, 73, 95-101. [CrossRef]

96. Villareal, D.T.; Chode, S.; Parimi, N.; Sinacore, D.R.; Hilton, T.; Armamento-Villareal, R.; Napoli, N.; Qualls, C.; Shah, K. Weight Loss, Exercise, or Both and Physical Function in Obese Older Adults. N. Engl. J. Med. 2011, 364, 1218-1229. [CrossRef]

97. Nicklas, B.J.; Wang, X.; You, T.; Lyles, M.F.; Demons, J.; Easter, L.; Berry, M.J.; Lenchik, L.; Carr, J.J. Effect of exercise intensity on abdominal fat loss during calorie restriction in overweight and obese postmenopausal women: A randomized, controlled trial. Am. J. Clin. Nutr. 2009, 89, 1043-1052. [CrossRef]

98. Amati, F.; Dube, J.J.; Shay, C.; Goodpaster, B.H. Separate and combined effects of exercise training and weight loss on exercise efficiency and substrate oxidation. J. Appl. Physiol. 2008, 105, 825-831. [CrossRef]

99. Foster-Schubert, K.E.; Alfano, C.M.; Duggan, C.R.; Xiao, L.; Campbell, K.L.; Kong, A.; Bain, C.E.; Wang, C.-Y.; Blackburn, G.L.; McTiernan, A. Effect of diet and exercise, alone or combined, on weight and body composition in overweight-to-obese postmenopausal women. Obesity (Silver Spring) 2012, 20, 1628-1638. [CrossRef]

100. Swank, A.M.; Horton, J.; Fleg, J.L.; Fonarow, G.C.; Keteyian, S.; Goldberg, L.; Wolfel, G.; Handberg, E.M.; Bensimhon, D.; Illiou, M.-C.; et al. Modest increase in peak VO2 is related to better clinical outcomes in chronic heart failure patients: Results from heart failure and a controlled trial to investigate outcomes of exercise training. Circ. Heart Fail. 2012, 5, 579-585. [CrossRef]

101. Kondamudi, N.; Haykowsky, M.; Forman, D.E.; Berry, J.D.; Pandey, A. Exercise Training for Prevention and Treatment of Heart Failure. Prog. Cardiovasc. Dis. 2017, 60, 115-120. [CrossRef] [PubMed] 
102. Haykowsky, M.J.; Tomczak, C.R.; Scott, J.M.; Paterson, D.I.; Kitzman, D.W. Determinants of exercise intolerance in patients with heart failure and reduced or preserved ejection fraction. J. Appl. Physiol. 2015, 119, 739-744. [CrossRef] [PubMed]

103. Carbone, S.; Canada, J.M.; Buckley, L.F.; Trankle, C.R.; Dixon, D.L.; Buzzetti, R.; Arena, R.; Van Tassell, B.W.; Abbate, A. Obesity Contributes to Exercise Intolerance in Heart Failure with Preserved Ejection Fraction. J. Am. Coll. Cardiol. 2016, 68, 2487-2488. [CrossRef] [PubMed]

104. Obokata, M.; Reddy, Y.N.V.; Pislaru, S.V.; Melenovsky, V.; Borlaug, B.A. Evidence Supporting the Existence of a Distinct Obese Phenotype of Heart Failure with Preserved Ejection Fraction. Circulation 2017, 136, 6-19. [CrossRef]

105. DiNicolantonio, J.J.; Niazi, A.K.; Lavie, C.J.; O’Keefe, J.H.; Ventura, H.O. Thiamine Supplementation for the Treatment of Heart Failure: A Review of the Literature. Congest. Hear. Fail. 2013, 19, 214-222. [CrossRef]

106. Norman, K.; Stobäus, N.; Pirlich, M.; Bosy-Westphal, A. Bioelectrical phase angle and impedance vector analysis-Clinical relevance and applicability of impedance parameters. Clin. Nutr. 2012, 31, 854-861. [CrossRef]

107. Araújo, J.P.; Lourenço, P.; Rocha-Gonçalves, F.; Ferreira, A.; Bettencourt, P. Nutritional markers and prognosis in cardiac cachexia. Int. J. Cardiol. 2011, 146, 359-363. [CrossRef]

108. Bittner, V.; Weiner, D.H.; Yusuf, S.; Rogers, W.J.; McIntyre, K.M.; Bangdiwala, S.I.; Kronenberg, M.W.; Kostis, J.B.; Kohn, R.M.; Guillotte, M.; et al. Prediction of Mortality and Morbidity with a 6-Minute Walk Test in Patients with Left Ventricular Dysfunction. JAMA 1993, 270, 1702-1707. [CrossRef]

109. Coats, A.J.S.; Pieske, B.; Linde, C.; Jankowska, E.A.; Ruschitzka, F.; Rutten, F.H.; Rosano, G.M.C.; Bueno, H.; Riley, J.P.; Cleland, J.G.F.; et al. 2016 ESC Guidelines for the diagnosis and treatment of acute and chronic heart failure: The Task Force for the diagnosis and treatment of acute and chronic heart failure of the European Society of Cardiology (ESC)Developed with the special contribution of. Eur. Heart J. 2016, 37, 2129-2200.

110. Abbate, A.; Arena, R.; Abouzaki, N.; Van Tassell, B.W.; Canada, J.; Shah, K.; Biondi-Zoccai, G.; Voelkel, N.F. Heart failure with preserved ejection fraction: Refocusing on diastole. Int. J. Cardiol. 2015, 179, 430-440. [CrossRef]

111. Del Buono, M.G.; Buckley, L.; Abbate, A. Primary and Secondary Diastolic Dysfunction in Heart Failure with Preserved Ejection Fraction. Am. J. Cardiol. 2018, 122, 1578-1587. [CrossRef] [PubMed]

112. Savji, N.; Meijers, W.C.; Bartz, T.M.; Bhambhani, V.; Cushman, M.; Nayor, M.; Kizer, J.R.; Sarma, A.; Blaha, M.J.; Gansevoort, R.T.; et al. The Association of Obesity and Cardiometabolic Traits with Incident HFpEF and HFrEF. JACC. Heart Fail. 2018, 6, 701-709. [CrossRef] [PubMed]

113. Kitzman, D.W.; Shah, S.J. The HFpEF Obesity Phenotype. J. Am. Coll. Cardiol. 2016, 68, 200-203. [CrossRef] [PubMed]

114. Carbone, S.; Canada, J.M.; Antonio, A. Letter by Carbone et al Regarding Article, "Evidence Supporting the Existence of a Distinct Obese Phenotype of Heart Failure with Preserved Ejection Fraction". Circulation 2018, 137, 414-415. [CrossRef]

115. Carbone, S.; Pandey, A.; Lavie, C.J. Editorial commentary: Obesity and heart failure with preserved ejection fraction: A single disease or two co-existing conditions? Trends Cardiovasc. Med. 2018, 28, 328-329. [CrossRef]

116. Upadhya, B.; Haykowsky, M.J.; Eggebeen, J.; Kitzman, D.W. Exercise intolerance in heart failure with preserved ejection fraction: More than a heart problem. J. Geriatr. Cardiol. 2015, 12, 294-304.

117. Oh, A.; Okazaki, R.; Sam, F.; Valero-Muñoz, M. Heart Failure with Preserved Ejection Fraction and Adipose Tissue: A Story of Two Tales. Front. Cardiovasc. Med. 2019, 6, 110. [CrossRef]

118. Carbone, S.; Canada, J.M.; Billingsley, H.E.; Siddiqui, M.S.; Elagizi, A.; Lavie, C.J. Obesity paradox in cardiovascular disease: Where do we stand? Vasc. Health Risk Manag. 2019, 15, 89-100. [CrossRef]

119. Billingsley, H.; Carbone, S.; Lavie, C. Dietary Fats and Chronic Noncommunicable Diseases. Nutrients 2018, 10, 1385. [CrossRef]

120. Hummel, S.L.; Karmally, W.; Gillespie, B.W.; Helmke, S.; Teruya, S.; Wells, J.; Trumble, E.; Jimenez, O.; Marolt, C.; Wessler, J.D.; et al. Home-Delivered Meals Postdischarge from Heart Failure Hospitalization. Circ. Hear. Fail. 2018, 11, e004886. [CrossRef]

121. Booth, F.W.; Roberts, C.K.; Laye, M.J. Lack of exercise is a major cause of chronic diseases. Compr. Physiol. 2012, 2, 1143-1211. [PubMed] 
122. Ekkekakis, P.; Vazou, S.; Bixby, W.R.; Georgiadis, E. The mysterious case of the public health guideline that is (almost) entirely ignored: Call for a research agenda on the causes of the extreme avoidance of physical activity in obesity. Obes. Rev. 2016, 17, 313-329. [CrossRef] [PubMed]

123. Deedwania, P.; Lavie, C.J. Dangers and Long-Term Outcomes in Metabolically Healthy Obesity: The Impact of the Missing Fitness Component*. J. Am. Coll. Cardiol. 2018, 71, 1866-1868. [CrossRef] [PubMed]

124. Lavie, C.J.; Laddu, D.; Arena, R.; Ortega, F.B.; Alpert, M.A.; Kushner, R.F. Healthy Weight and Obesity Prevention: JACC Health Promotion Series. J. Am. Coll. Cardiol. 2018, 72, 1506-1531. [CrossRef] [PubMed]

125. Arena, R.; Cahalin, L.P. Evaluation of cardiorespiratory fitness and respiratory muscle function in the obese population. Prog. Cardiovasc. Dis. 2014, 56, 457-464. [CrossRef] [PubMed]

126. Ortega, F.B.; Ruiz, J.R.; Labayen, I.; Lavie, C.J.; Blair, S.N. The Fat but Fit paradox: What we know and don't know about it. Br. J. Sports Med. 2018, 52, 151-153. [CrossRef]

127. Jensen, M.D.; Ryan, D.H.; Apovian, C.M.; Ard, J.D.; Comuzzie, A.G.; Donato, K.A.; Hu, F.B.; Hubbard, V.S.; Jakicic, J.M.; Kushner, R.F.; et al. 2013 AHA/ACC/TOS Guideline for the Management of Overweight and Obesity in Adults. Circulation 2013, 129, S102-S138. [CrossRef]

128. Straznicky, N.E.; Lambert, E.A.; Nestel, P.J.; McGrane, M.T.; Dawood, T.; Schlaich, M.P.; Masuo, K.; Eikelis, N.; de Courten, B.; Mariani, J.A.; et al. Sympathetic neural adaptation to hypocaloric diet with or without exercise training in obese metabolic syndrome subjects. Diabetes 2010, 59, 71-79. [CrossRef]

129. Brinkworth, G.D.; Noakes, M.; Clifton, P.M.; Buckley, J.D. Effects of a low carbohydrate weight loss diet on exercise capacity and tolerance in obese subjects. Obesity (Silver Spring) 2009, 17, 1916-1923. [CrossRef]

130. Wycherley, T.P.; Buckley, J.D.; Noakes, M.; Clifton, P.M.; Brinkworth, G.D. Long-term effects of a very low-carbohydrate weight loss diet on exercise capacity and tolerance in overweight and obese adults. J. Am. Coll. Nutr. 2014, 33, 267-273. [CrossRef]

131. Wycherley, T.P.; Buckley, J.D.; Noakes, M.; Clifton, P.M.; Brinkworth, G.D. Comparison of the effects of weight loss from a high-protein versus standard-protein energy-restricted diet on strength and aerobic capacity in overweight and obese men. Eur. J. Nutr. 2013, 52, 317-325. [CrossRef] [PubMed]

132. Cruz-Jentoft, A.J.; Sayer, A.A.; Schneider, S.M.; Sieber, C.C.; Topinkova, E.; Vandewoude, M.; Visser, M.; Zamboni, M.; Bahat, G.; Bauer, J.; et al. Sarcopenia: Revised European consensus on definition and diagnosis. Age Ageing 2018, 48, 16-31. [CrossRef] [PubMed]

133. de Oliveira, R.J.; Bottaro, M.; Motta, A.M.; Pitanga, F.; Guido, M.; Leite, T.K.M.; Bezerra, L.M.A.; Lima, R.M. Association between sarcopenia-related phenotypes and aerobic capacity indexes of older women. J. Sports Sci. Med. 2009, 8, 337-343. [PubMed]

134. Jung, M.-H.; Ihm, S.-H.; Park, S.M.; Jung, H.O.; Hong, K.-S.; Baek, S.H.; Youn, H.-J. Effects of sarcopenia, body mass indices, and sarcopenic obesity on diastolic function and exercise capacity in Koreans. Metabolism 2019, 97, 18-24. [CrossRef]

135. Emami, A.; Saitoh, M.; Valentova, M.; Sandek, A.; Evertz, R.; Ebner, N.; Loncar, G.; Springer, J.; Doehner, W.; Lainscak, M.; et al. Comparison of sarcopenia and cachexia in men with chronic heart failure: Results from the Studies Investigating Co-morbidities Aggravating Heart Failure (SICA-HF). Eur. J. Heart Fail. 2018, 20, 1580-1587. [CrossRef]

136. Prior, S.J.; Ryan, A.S.; Blumenthal, J.B.; Watson, J.M.; Katzel, L.I.; Goldberg, A.P. Sarcopenia Is Associated With Lower Skeletal Muscle Capillarization and Exercise Capacity in Older Adults. J. Gerontol. A Biol. Sci. Med. Sci. 2016, 71, 1096-1101. [CrossRef]

137. Morard, M.-D.; Besson, D.; Laroche, D.; Naaïm, A.; Gremeaux, V.; Casillas, J.-M. Fixed-distance walk tests at comfortable and fast speed: Potential tools for the functional assessment of coronary patients? Ann. Phys. Rehabil. Med. 2017, 60, 13-19. [CrossRef]

138. Cruz-Jentoft, A.J.; Kiesswetter, E.; Drey, M.; Sieber, C.C. Nutrition, frailty, and sarcopenia. Aging Clin. Exp. Res. 2017, 29, 43-48. [CrossRef]

139. Cruz-Jentoft, A.J.; Landi, F.; Schneider, S.M.; Zuniga, C.; Arai, H.; Boirie, Y.; Chen, L.-K.; Fielding, R.A.; Martin, F.C.; Michel, J.-P.; et al. Prevalence of and interventions for sarcopenia in ageing adults: A systematic review. Report of the International Sarcopenia Initiative (EWGSOP and IWGS). Age Ageing 2014, 43, 748-759. [CrossRef]

140. Bibiloni, M.D.M.; Julibert, A.; Argelich, E.; Aparicio-Ugarriza, R.; Palacios, G.; Pons, A.; Gonzalez-Gross, M.; Tur, J.A. Western and Mediterranean Dietary Patterns and Physical Activity and Fitness among Spanish Older Adults. Nutrients 2017, 9, 704. [CrossRef] 
141. Tepper, S.; Alter Sivashensky, A.; Rivkah Shahar, D.; Geva, D.; Cukierman-Yaffe, T. The Association between Mediterranean Diet and the Risk of Falls and Physical Function Indices in Older Type 2 Diabetic People Varies by Age. Nutrients 2018, 10, 767. [CrossRef] [PubMed]

142. Fielding, R.A.; Travison, T.G.; Kirn, D.R.; Koochek, A.; Reid, K.F.; von Berens, Å.; Zhu, H.; Folta, S.C.; Sacheck, J.M.; Nelson, M.E.; et al. Effect of structured physical activity and nutritional supplementation on physical function in mobility-limited older adults: Results from the VIVE2 randomized trial. J. Nutr. Health Aging 2017, 21, 936-942. [CrossRef] [PubMed]

143. Chen, L.-K.; Liu, L.-K.; Woo, J.; Assantachai, P.; Auyeung, T.-W.; Bahyah, K.S.; Chou, M.-Y.; Chen, L.-Y.; Hsu, P.-S.; Krairit, O.; et al. Sarcopenia in Asia: Consensus Report of the Asian Working Group for Sarcopenia. J. Am. Med. Dir. Assoc. 2014, 15, 95-101. [CrossRef] [PubMed]

144. Kirkman, D.L.; Muth, B.J.; Stock, J.M.; Townsend, R.R.; Edwards, D.G. Cardiopulmonary exercise testing reveals subclinical abnormalities in chronic kidney disease. Eur. J. Prev. Cardiol. 2018, 25, 1717-1724. [CrossRef] [PubMed]

145. Roshanravan, B.; Robinson-Cohen, C.; Patel, K.V.; Ayers, E.; Littman, A.J.; de Boer, I.H.; Ikizler, T.A.; Himmelfarb, J.; Katzel, L.I.; Kestenbaum, B.; et al. Association between physical performance and all-cause mortality in CKD. J. Am. Soc. Nephrol. 2013, 24, 822-830. [CrossRef]

146. Jones, L.W.; Eves, N.D.; Haykowsky, M.; Freedland, S.J.; Mackey, J.R. Exercise intolerance in cancer and the role of exercise therapy to reverse dysfunction. Lancet. Oncol. 2009, 10, 598-605. [CrossRef]

147. Vinke, P.; Jansen, S.M.; Witkamp, R.F.; van Norren, K. Increasing quality of life in pulmonary arterial hypertension: Is there a role for nutrition? Heart Fail. Rev. 2018, 23, 711-722. [CrossRef]

148. Canada, J.M.; Abbate, A.; Collen, R.; Billingsley, H.; Buckley, L.F.; Carbone, S.; Trankle, C.R.; Idowu, M.O.; Kadariya, D.; Van Tassell, B.; et al. Relation of Hepatic Fibrosis in Nonalcoholic Fatty Liver Disease to Left Ventricular Diastolic Function and Exercise Tolerance. Am. J. Cardiol. 2019, 123, 466-473. [CrossRef]

149. Van Gelder, I.C.; Hobbelt, A.H.; Brügemann, J.; Rienstra, M. Time to implement fitness and reduction of fatness in atrial fibrillation therapy. EP Eur. 2016, 19, 513-514. [CrossRef]

150. Ikizler, T.A.; Robinson-Cohen, C.; Ellis, C.; Headley, S.A.E.; Tuttle, K.; Wood, R.J.; Evans, E.E.; Milch, C.M.; Moody, K.A.; Germain, M.; et al. Metabolic Effects of Diet and Exercise in Patients with Moderate to Severe CKD: A Randomized Clinical Trial. J. Am. Soc. Nephrol. 2018, 29, 250-259. [CrossRef]

151. Snelson, M.; Clarke, E.R.; Coughlan, T.M. Stirring the Pot: Can Dietary Modification Alleviate the Burden of CKD? Nutrients 2017, 9, 265. [CrossRef]

152. Sheppard, V.B.; Hicks, J.; Makambi, K.; Hurtado-de-Mendoza, A.; Demark-Wahnefried, W.; Adams-Campbell, L. The feasibility and acceptability of a diet and exercise trial in overweight and obese black breast cancer survivors: The Stepping STONE study. Contemp. Clin. Trials 2016, 46, 106-113. [CrossRef]

153. O'Neill, L.M.; Guinan, E.; Doyle, S.L.; Bennett, A.E.; Murphy, C.; Elliott, J.A.; O'Sullivan, J.; Reynolds, J.V.; Hussey, J. The RESTORE Randomized Controlled Trial: Impact of a Multidisciplinary Rehabilitative Program on Cardiorespiratory Fitness in Esophagogastric cancer Survivorship. Ann. Surg. 2018, 268, 747-755. [CrossRef] [PubMed]

154. Travier, N.; Buckland, G.; Vendrell, J.J.; Fernandez-Veledo, S.; Peiro, I.; Del Barco, S.; Pernas, S.; Zamora, E.; Bellet, M.; Margeli, M.; et al. Changes in metabolic risk, insulin resistance, leptin and adiponectin following a lifestyle intervention in overweight and obese breast cancer survivors. Eur. J. Cancer Care (Engl.) 2018, 27, e12861. [CrossRef]

155. Ludwig, D.S.; Ebbeling, C.B.; Heymsfield, S.B. Improving the Quality of Dietary ResearchImproving the Quality of Dietary ResearchImproving the Quality of Dietary Research. JAMA 2019, 322, 1549-1550. [CrossRef]

(C) 2019 by the authors. Licensee MDPI, Basel, Switzerland. This article is an open access article distributed under the terms and conditions of the Creative Commons Attribution (CC BY) license (http://creativecommons.org/licenses/by/4.0/). 